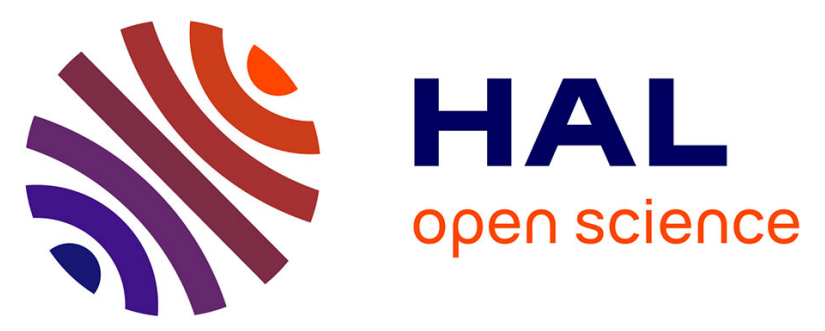

\title{
Simple access to alkoxysilyl telechelic polyolefins from ruthenium-catalyzed cross-metathesis depolymerization of polydienes
}

\author{
Xiaolu Michel, Stéphane Fouquay, Guillaume Michaud, Frédéric Simon, \\ Jean-Michel Brusson, Jean-François Carpentier, Sophie M. Guillaume
}

\section{To cite this version:}

Xiaolu Michel, Stéphane Fouquay, Guillaume Michaud, Frédéric Simon, Jean-Michel Brusson, et al.. Simple access to alkoxysilyl telechelic polyolefins from ruthenium-catalyzed crossmetathesis depolymerization of polydienes. European Polymer Journal, 2017, 96, pp.403-413. 10.1016/j.eurpolymj.2017.09.027 . hal-01639683

\section{HAL Id: hal-01639683}

https://hal-univ-rennes1.archives-ouvertes.fr/hal-01639683

Submitted on 16 Mar 2018

HAL is a multi-disciplinary open access archive for the deposit and dissemination of scientific research documents, whether they are published or not. The documents may come from teaching and research institutions in France or abroad, or from public or private research centers.
L'archive ouverte pluridisciplinaire HAL, est destinée au dépôt et à la diffusion de documents scientifiques de niveau recherche, publiés ou non, émanant des établissements d'enseignement et de recherche français ou étrangers, des laboratoires publics ou privés. 


\section{Simple Access to Alkoxysilyl Telechelic Polyolefins from Ruthenium-Catalyzed Cross-}

\section{Metathesis Depolymerization of Polydienes}

Xiaolu Michel, ${ }^{\mathrm{a}}$ Stéphane Fouquay, ${ }^{\mathrm{b}}$ Guillaume Michaud, ${ }^{\mathrm{c}}$ Frédéric Simon, ${ }^{\mathrm{c}}$ Jean-Michel Brusson, ${ }^{\mathrm{d}}$ Jean-François Carpentier (ORCID: 0000-0002-9160-7662), ${ }^{\mathrm{a},{ }^{*}}$ and Sophie M. Guillaume (ORCID: 0000-0003-2917-8657) ${ }^{\mathrm{a}, *}$

${ }^{a}$ University of Rennes 1, CNRS, Institut des Sciences Chimiques de Rennes (ISCR), UMR 6226, F-35042 Rennes Cedex, France

${ }^{b}$ BOSTIK S.A., F-93211 La Plaine Saint-Denis, France

${ }^{c}$ BOSTIK S.A., F-60280 Venette, France

${ }^{d}$ Total S.A., Corporate Science, F-92069 Paris La Défense Cedex, France

*Corresponding authors: jean-francois.carpentier@univ-rennes1.fr; sophie.guillaume@univ-rennes1.fr 


\section{Abstract}

The first functional cross-metathesis (CM) depolymerization of commercial (co)polydienes using a ruthenium catalyst and an acyclic bis(trialkoxysilyl) difunctionalized chain-transfer agent (CTA), $\left[(\mathrm{EtO})_{3} \mathrm{Si}\left(\mathrm{CH}_{2}\right)_{3} \mathrm{NHC}(\mathrm{O}) \mathrm{OCH}_{2} \mathrm{CH}=\right]_{2}(\mathbf{1})$, towards the synthesis of low viscosity liquid $\alpha, \omega$-bis(trialkoxysilyl) telechelic (co)polydienes is reported. The reactivity of three commercial grades of liquid (co)polydienes (P1-P3, polybutadienes (PBDs) or poly(butadieneco-isoprene $)(\mathrm{P}(\mathrm{BD}-c o-\mathrm{IP})))$ differing in their end-functionalization and in the amount of 1,2vinyl and in their dispersity was explored. Operating conditions for effective production of $\alpha, \omega-$ bis(trialkoxysilyl) telechelic PBDs or P(BD-co-IP)s with high chemoselectivity (80-90wt\%) and catalytic productivity (non-optimized TON up to 24000 ) were established. The chemoselectivity of this tandem metathesis reaction was assessed in particular through detailed 2D NMR analyses. An original approach combining the CM depolymerization of PBD with the ring-opening functional metathesis polymerization (ROMP) of a cycloolefin in the presence of CTA 1 has also been next implemented affording low viscosity liquid $\alpha, \omega$-bis(trialkoxysilyl) telechelic copolydienes. The viscosity of the (co)polyolefins was investigated by rheological analyses.

\section{Graphical abstract}

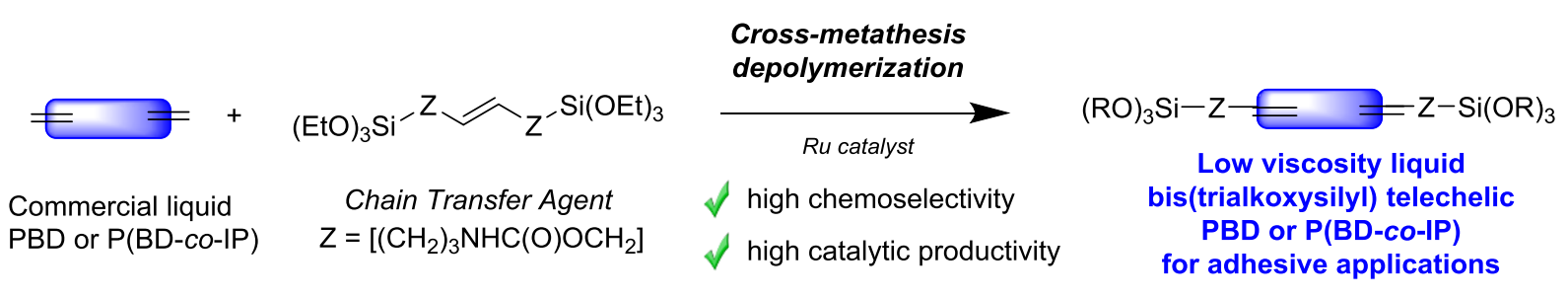




\section{HIGHLIGHTS}

-Functional cross-metathesis depolymerization of commercially available polydienes -Effective production of $\alpha, \omega$-bis(trialkoxysilyl) telechelic PBDs or P(BD-co-IP)s

-Cross-metathesis depolymerization of PBD combined to the ROMP of a cycloolefin

-Low viscosity liquid $\alpha, \omega$-bis(trialkoxysilyl) telechelic (co)polydienes 


\section{Introduction}

Silyl-modified polymers (SMPs) are silyloxy end-capped polymers acting as the main components in solvent-free, poly(vinyl chloride) (PVC)-free and isocyanate-free sealant and adhesive materials. Thanks to the alkoxysilyl functional groups, such polymers can be cured even at room temperature under the action of moisture arising from the surrounding environment and/or the substrate onto which it is applied, affording cohesive siloxane-bonded ( $\mathrm{Si}-\mathrm{O}-\mathrm{Si}$ ) networks. The resulting polysiloxanes exhibit temperature and UV resistance and excellent durability. 1,2,3,4,5,6,7,8,9,10,11,12,13,14 Bostik-Arkema, Evonik, Kaneka and Wacker are some of the major companies providing SMPs.

Within the scope of our ongoing studies on telechelic polymers prepared by metathesis, ${ }^{15,16,17}$ we have recently reported the efficient synthesis of $\alpha, \omega$-bis(trialkoxysilyl) functionalized polyolefins via Ru-catalyzed ring-opening metathesis (co)polymerization (ROMP)/cross-metathesis (CM) of cyclic olefins using various mono- or bis(trialkoxysilyl) functionalized alkenes as chain-transfer agents (CTAs). ${ }^{18,19,20}$ The high catalytic productivity (TurnOver Numbers, TONs, up to 90,000 mol(cycloolefin).mol(Ru) $\left.{ }^{-1}\right)$, high selectivity towards bis(trialkoxysilyl) telechelic polyolefins (typically $>85 \mathrm{wt} \%$ ), and low viscosity of the final liquid materials make these industrially relevant adhesive precursors. ${ }^{21,22,23,24,25,26,27,28}$ Indeed, in order to ensure effective formulation of adhesives and to maximize contact area and attractive forces between the adhesive and the bonding surface, targeted adhesive polymer precursors should be low viscosity liquids at ambient temperature. ${ }^{29}$

Polydienes may also be considered as valuable starting materials in such processes. Used commonly as adhesives and also as three of the major components used in tires, polybutadiene (PBD), polyisoprene (PIP) or poly(styrene-co-butadiene) (styrene butadiene rubber, SBR) have been successfully depolymerized via Ru, Mo, or W alkylidene-catalyzed 
metathesis in the presence of various CTAs to elaborate original functionalized polyolefins of lower molar mass (Scheme 1). Monofunctional CTAs such as vinyl, ${ }^{30}$ vinylsilane, ${ }^{31,32}$ allysilyl, ${ }^{33,34}$ acrylate, ${ }^{35}$ or difunctional CTAs such as disilyl, ${ }^{34,36}$ diester $^{34,36}$ or diphthalimide ${ }^{36,}$ alkene, ${ }^{37,38}$ have thus effectively enabled the preparation of (hemi)telechelic PBDs. Similarly, CM depolymerization of polyisoprene or rubbers (natural or synthetic) in organic solvents or ionic liquids ${ }^{39}$ using a CTA such as 4 -octene, ${ }^{37}$ or difunctionalized ones such as cis-1,4diacetoxy-2-butene, cis-but-2-ene-1,4-diol or a bis(trithiocarbonyl) derivative, successfully gave the corresponding telechelic polymers in very good yields (up to 98\%) with a good control of molar masses. ${ }^{39,40,41,42}$ Also, scrambling CM reactions between PBD or PIP and olefincontaining polyurethanes resulted in hybrid polyolefin/polyurethane materials with compositions ranging from multiblock to random and displaying enhanced mechanical properties. $^{43}$

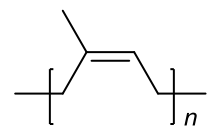

PIP<smiles>CC(C)(C)C/C=C/CC(C)(C)C</smiles>

PBD

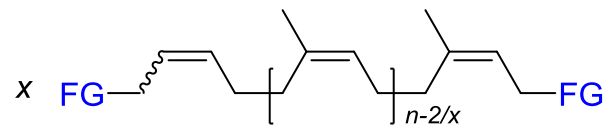

[Catalyst]

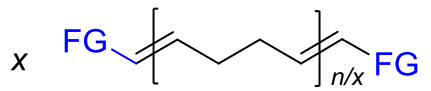

$\alpha, \omega-\operatorname{di}(F G) P B D$

Scheme 1. Metal alkylidene-catalyzed metathesis degradation of polyisoprene (PIP) or polybutadiene (PBD) in the presence of a bifunctional (biFG) symmetric alkene chain-transfer agent (CTA), affording $\alpha, \omega-\mathrm{FG}$ telechelic PIP and PBD, respectively.

We thus report herein the first $\mathrm{CM}$ depolymerization of commercial (co)polydienes using a bis(trialkoxysilyl) acyclic alkene CTA, namely $\left[(\mathrm{EtO})_{3} \mathrm{Si}\left(\mathrm{CH}_{2}\right)_{3} \mathrm{NHC}(=\mathrm{O}) \mathrm{OCH}_{2} \mathrm{CH}=\right]_{2}$ (1), previously optimized in our ROMP/CM studies,,${ }^{19,20}$ towards the synthesis of low viscosity liquid $\alpha, \omega$-bis(trialkoxysilyl) telechelic (co)polydienes (Schemes 2-4). Compared to the previously implemented ROMP/CM of cycloolefins strategy, ${ }^{18-20}$ the advantage of this 
depolymerization approach is the low cost of these liquid (co)polydienes (compared to cyclooctene, norbornene and other lab-made cycloolefins), and the easier handling of such reactants as compared to volatile cycloolefin monomers. Three commercial grades of liquid, low molar mass (co)polydienes $(\mathbf{P} \boldsymbol{x}, x=1-3)$ were chosen according to their industrial availability and viscosity (elastomers with $T_{g}=c a .-105^{\circ} \mathrm{C}$ ) (Scheme 2; Tables 1-3). ${ }^{44}$ The main differences between $\mathbf{P 1}$ and $\mathbf{P 2}$ lie in the functionalization, the amount of 1,2-vinyl PBD and the dispersity. P1 is a non-functionalized PBD containing only 1 mol\% of 1,2-vinyl with a narrow dispersity. P2 is end-functionalized by maleic anhydride and contains more 1,2-vinyl PBD than $\mathbf{P 1}$ while its dispersity is larger. P3 is an isoprene-butadiene (IP-BD) copolymer, $\mathrm{P}(\mathrm{BD}-\mathrm{co}-\mathrm{IP})$, containing $90 \mathrm{~mol} \%$ of $\mathrm{PBD}$ with a narrow dispersity (Table 1). Operating conditions for an effective P1-P3 metathesis depolymerization/CM were first optimized to produce well-defined $\alpha, \omega$-bis(trialkoxysilyl) telechelic PBDs or $\mathrm{P}(\mathrm{BD}-c o-\mathrm{IP}) \mathrm{s}$ with high chemoselectivity and catalytic productivity (Schemes 2, 4; Table 2). An original approach combining CM depolymerization of PBD with ROMP/CM of a cycloolefin has next been implemented towards low viscosity liquid $\alpha, \omega$-bis(trialkoxysilyl) telechelic copolydienes (Scheme 3; Table 3). Preliminary rheological analyses were performed to investigate the viscosity of the (co)polyolefins (Table 4).

Table 1. Characteristics of the commercial liquid (co)polydienes selected for this study.

\begin{tabular}{|c|c|c|c|c|c|}
\hline Polydiene & Supplier & $F n^{a}$ & Composition & $\begin{array}{l}M_{\mathrm{n}, \mathrm{SEC}}{ }^{b} \\
\left(\mathrm{~g} \cdot \mathrm{mol}^{-1}\right)\end{array}$ & $\bigoplus_{M}{ }^{b}$ \\
\hline $\begin{array}{l}\text { Polyvest }{ }^{\circledR} 110 \\
\text { PBD } \\
(\text { P1 })\end{array}$ & Evonik & - & $\begin{array}{c}\text { 1mol\% 1,2-vinyl PBD, } \\
\text { 24mol\% 1,4-cis PBD, } \\
\text { 75mol\% 1,4-trans PBD } \\
\text { (supplier data) }\end{array}$ & 8100 & 1.2 \\
\hline $\begin{array}{c}\text { Ricon } ₫ 130 \mathrm{MA} 8 \\
\text { PBD } \\
(\text { P2) }\end{array}$ & $\begin{array}{l}\text { Cray } \\
\text { Valley }\end{array}$ & $\begin{array}{c}\text { Maleic } \\
\text { anhydride }\end{array}$ & $\begin{array}{c}\text { 20-35mol\% 1,2-vinyl PBD } \\
\text { (supplier data) }\end{array}$ & 5300 & 2.1 \\
\hline
\end{tabular}




\begin{tabular}{ccccc}
\hline LIR390 & & {$[\mathrm{IP}]_{0} /[\mathrm{BD}]_{0}=10: 90$} & 20000 & 1.1 \\
$\begin{array}{c}\text { P(BD-co-IP }) \\
(\mathbf{P 3})\end{array}$ & Kuraray & - & $\left(\right.$ experimental ${ }^{1} \mathrm{H}$ NMR data) & \\
\hline
\end{tabular}

${ }^{a} F n=$ functionalization. ${ }^{b}$ Number-average molar mass $\left(M_{\mathrm{n}, \mathrm{SEC}}\right)$ and dispersity $\left(\bigoplus_{\mathrm{M}}=M_{\mathrm{w}} / M_{\mathrm{n}}\right)$ values as determined by SEC vs. polystyrene standards in THF at $30{ }^{\circ} \mathrm{C}$.

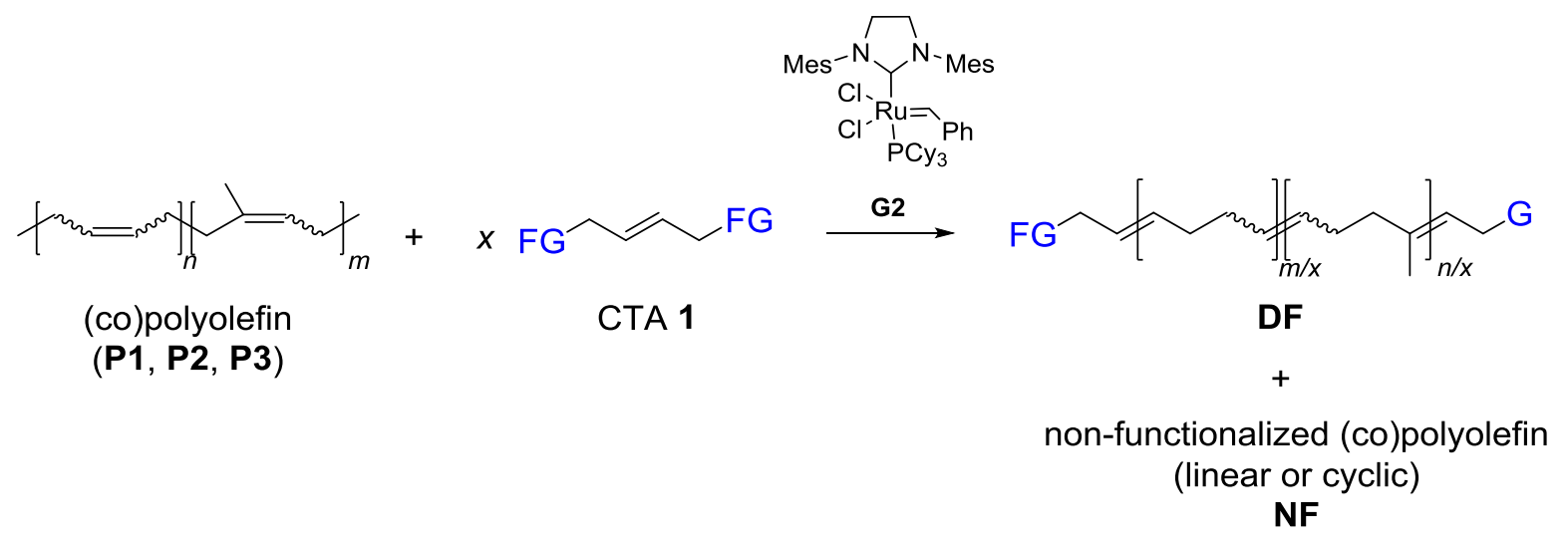<smiles>CC(C)(C)C/C=C\CC(C)(C)C</smiles><smiles>CC(C)(C)C/C=C/CC(C)(C)C</smiles>

1,4-cis PBD<smiles>C=CC(C)CC</smiles>

1,2-vinyl PBD

CTA 1<smiles>CCOCCCCNC(=O)OC/C=C/COC(=O)NCCC[SiH2]OCC</smiles>

Scheme 2. Functional metathesis depolymerization reactions of PBDs (P1, P2) or P(BD-co-IP) (P3) (co)polymers using Grubbs' $2^{\text {nd }}$ generation catalyst $(\mathbf{G} 2)$ in the presence of CTA 1 investigated in this work, affording $\alpha, \omega$-bis(trialkoxysilyl) telechelic (co)polyolefins (DF) possibly along with non-functionalized (co)polyolefins (NF). 


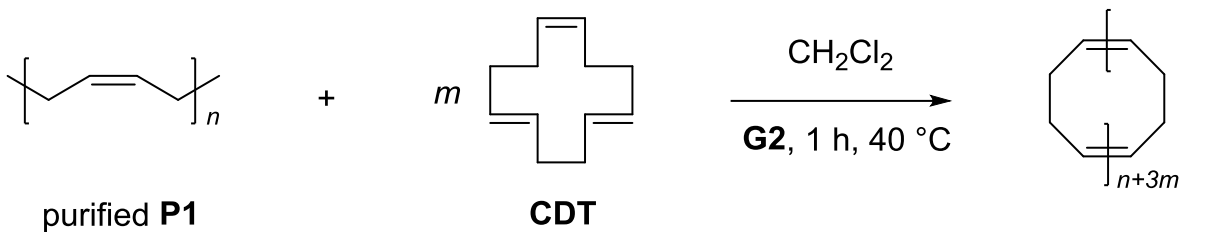

$x$ CTA 1

removal of $\mathrm{CH}_{2} \mathrm{Cl}_{2}$

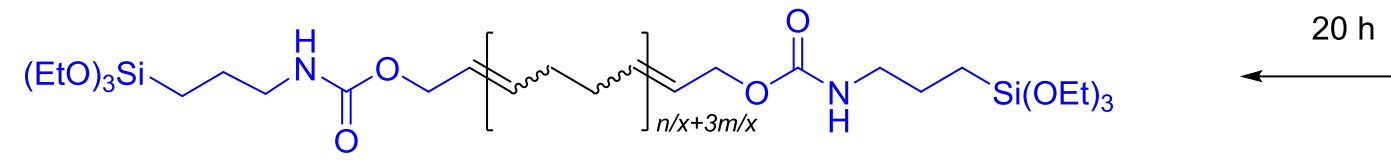

$\alpha, \omega-\mathrm{di}\left[\mathrm{Si}(\mathrm{OEt})_{3}\right] \mathrm{P}(\mathrm{BD}-\mathrm{co}-\mathrm{CDT})$

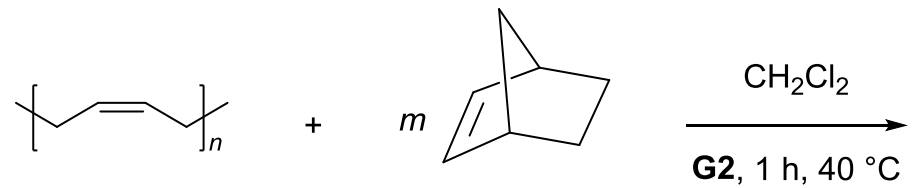

purified P1

NB
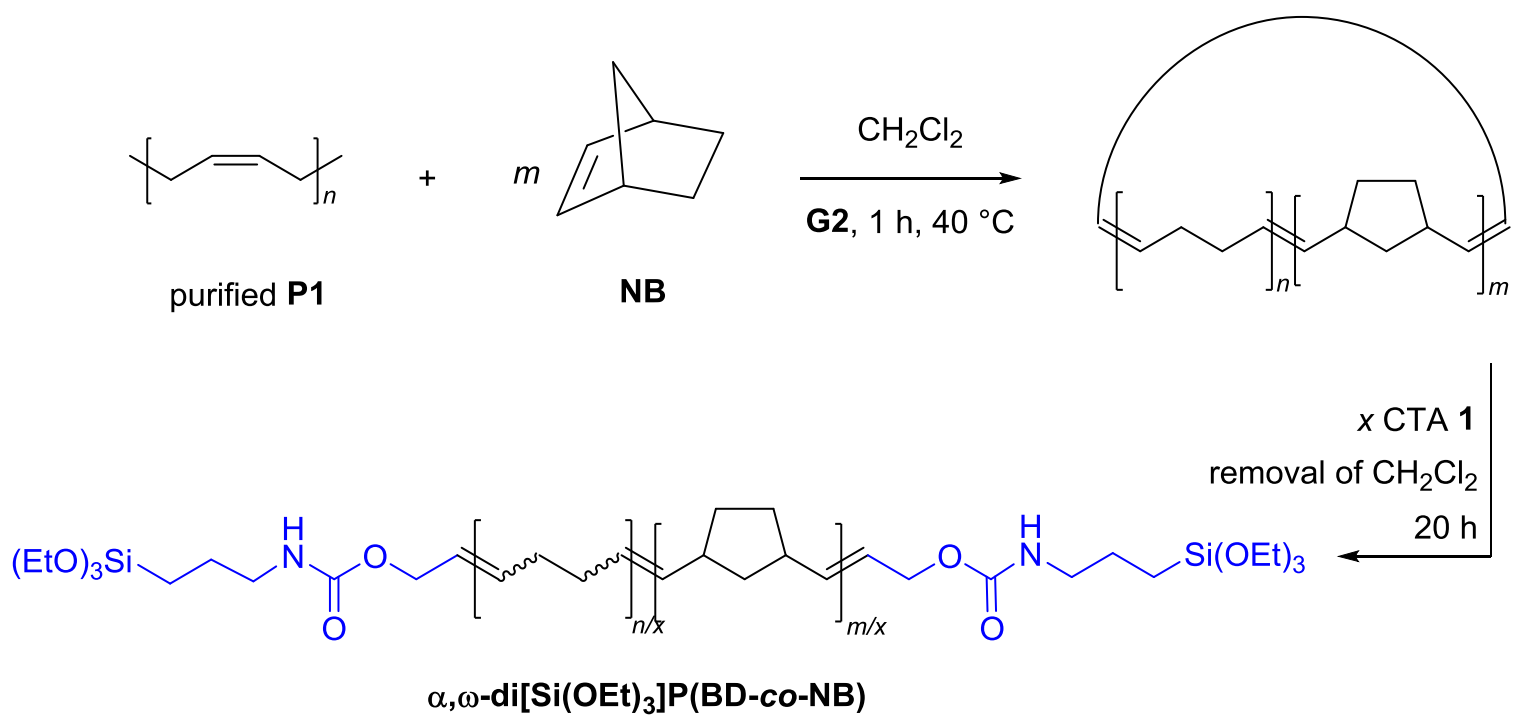

Scheme 3. Tandem functional depolymerization-ROMP/CM of PBD P1 and CDT or NB using G2 catalyst in the presence of CTA 1, affording $\alpha, \omega$-bis(trialkoxysilyl) telechelic (co)polyolefins (DF), $\mathrm{P}(\mathrm{BD}-c o-\mathrm{CDT})$ and $\mathrm{P}(\mathrm{BD}-c o-\mathrm{NB})$.

\section{Results and Discussion}

Synthesis of $\alpha, \omega$-bis(trialkoxysilyl) telechelic polyolefins. Low molar mass (co)polydienes P1-P3, which are grades typically used in adhesive-type applications,${ }^{45}$ were engaged in CM depolymerization using Grubbs' $2^{\text {nd }}$ generation (G2) catalyst in the presence of CTA 1, affording $\alpha, \omega$-bis(trialkoxysilyl) telechelic polyolefins (Scheme 2). All reactions were at least duplicated and eventually showed a quite good reproducibility of the CTA conversion and macromolecular data $( \pm 10 \%)$. Representative results are summarized in Table 2 . 
Table 2. Functional CM depolymerization of (co)polydienes P1-P3 using $\mathbf{G 2}$ in the presence of CTA 1 at $40{ }^{\circ} \mathrm{C}$ (unless otherwise stated).

\begin{tabular}{|c|c|c|c|c|c|c|c|c|c|c|c|c|c|c|}
\hline \multirow[b]{2}{*}{ Entry } & \multirow[b]{2}{*}{ Polydiene $^{a}$} & \multirow[b]{2}{*}{ Purif. ${ }^{b}$} & \multirow[b]{2}{*}{ Solvent } & \multirow{2}{*}{$\begin{array}{l}\text { Reaction } \\
\text { time }^{c} \\
\text { (h) }\end{array}$} & \multirow{2}{*}{$\begin{array}{c}{[\mathbf{P x}]_{0} /[\mathrm{CTA} \mathbf{1}]_{0}} \\
/[\mathbf{G 2}]_{0}\end{array}$} & \multirow{2}{*}{$\begin{array}{l}\text { CTA } 1 \\
\text { Conv. }{ }^{d} \\
\text { (mol\%) }\end{array}$} & \multirow{2}{*}{$\begin{array}{c}\mathbf{D F}^{e} \\
(\mathrm{wt} \%)\end{array}$} & \multirow{2}{*}{$\begin{array}{c}\mathbf{N F}^{e} \\
(\mathrm{wt} \%)\end{array}$} & \multicolumn{4}{|c|}{$\mathrm{DF}+\mathrm{NF}$} & \multicolumn{2}{|c|}{ NF } \\
\hline & & & & & & & & & $\begin{array}{c}M_{\mathrm{n}, \text { theo }}^{f} \\
\left(\mathrm{~g} \cdot \mathrm{mol}^{-1}\right)\end{array}$ & $\begin{array}{c}M_{\mathrm{n}, \mathrm{NMR}^{g}}{ }^{-1} \\
\left(\mathrm{~g} \cdot \mathrm{mol}^{-1}\right)\end{array}$ & $\begin{array}{c}M_{\mathrm{n}, \mathrm{SEC}}{ }^{h} \\
\left(\mathrm{~g} \cdot \mathrm{mol}^{-1}\right)\end{array}$ & $\bigoplus_{M}^{h}$ & $\begin{array}{l}M_{\mathrm{n}, \mathrm{SEC}}{ }^{h} \\
\left(\mathrm{~g} \cdot \mathrm{mol}^{-1}\right)\end{array}$ & $\bigoplus_{M}{ }^{h}$ \\
\hline 1 & P1 & - & $\mathrm{CH}_{2} \mathrm{Cl}_{2}$ & 24 & 3000:100:1 & 0 & 0 & 100 & - & - & 4200 & 1.9 & 4200 & 1.9 \\
\hline 2 & P1 & - & - & $3+20$ & 3000:100:1 & 32 & 20 & 80 & 5200 & 10900 & 2000 & 2.0 & 3300 & 1.8 \\
\hline 3 & $\mathbf{P 2}$ & - & - & $3+20$ & 3000:100:1 & 12 & 18 & 82 & 14000 & 19300 & 1800 & 2.0 & 3500 & 1.7 \\
\hline 4 & P1 & M1 & - & $3+20$ & 3000:100:1 & 100 & 76 & 24 & 2200 & 2100 & 3100 & 2.5 & 3600 & 1.6 \\
\hline 5 & $\mathbf{P 2}$ & M1 & - & $3+20$ & 3000:100:1 & 55 & 24 & 76 & 3000 & 3000 & 1700 & 2.0 & 3300 & 1.9 \\
\hline 6 & P1 & M2 & - & $3+20$ & 3000:100:1 & 100 & 68 & 32 & 2200 & 2100 & 2850 & 2.4 & 3200 & 2.3 \\
\hline 7 & P1 & M3 & - & $3+20$ & 3000:100:1 & 100 & 73 & 27 & 2200 & 2100 & 2770 & 2.3 & 3300 & 2.3 \\
\hline 8 & P1 & M1 & - & $10+20$ & 3000:100:1 & 39 & 38 & 62 & 2200 & 2200 & 2800 & 2.4 & 3200 & 2.3 \\
\hline 9 & P1 & M1 & - & $1+20$ & 3000:100:1 & 100 & 79 & 21 & 2200 & 1700 & 3200 & 1.6 & 2200 & 1.8 \\
\hline 10 & P1 & M1 & - & $3+20$ & 3000:100:1+1 & 100 & 79 & 21 & 2200 & 2100 & 2500 & 2.3 & 3600 & 2.5 \\
\hline $11^{\mathrm{i}}$ & P1 & M1 & - & $3+20$ & $3000: 100: 1^{\mathrm{i}}$ & 100 & 80 & 20 & 2200 & 1800 & 3300 & 1.6 & 3900 & 1.7 \\
\hline 12 & P1 & M1 & - & $3+20$ & 1000:10:1 & 100 & 77 & 23 & 5400 & 4800 & 2300 & 2.2 & 3500 & 2.6 \\
\hline 13 & P1 & M1 & - & $3+20$ & 3000:30:1 & 100 & 57 & 43 & 6000 & 5900 & 4600 & 2.4 & 4300 & 1.8 \\
\hline 14 & P1 & M1 & - & $3+20$ & 25 000:250:1 & 0 & 0 & 100 & - & - & 4300 & 1.7 & - & - \\
\hline 15 & P3 & - & $\mathrm{CH}_{2} \mathrm{Cl}_{2}$ & 24 & 3000:100:1 & 100 & 97 & 3 & 1600 & 1500 & 150 & 2.2 & 830 & 2.6 \\
\hline 16 & P3 & - & $\mathrm{CH}_{2} \mathrm{Cl}_{2}$ & 24 & 6000:80:1 & 100 & 95 & 5 & 4100 & 3900 & 160 & 2.7 & 780 & 2.5 \\
\hline 17 & P3 & - & $\mathrm{CH}_{2} \mathrm{Cl}_{2}$ & 24 & 6000:40:1 & 100 & 92 & 8 & 8200 & 7800 & 170 & 2.8 & 830 & 2.6 \\
\hline 18 & P3 & - & $\mathrm{CH}_{2} \mathrm{Cl}_{2}$ & 24 & 6000:20:1 & 100 & 91 & 9 & 16400 & 18000 & 180 & 2.7 & 840 & 3.1 \\
\hline 19 & P3 & - & $\mathrm{CH}_{2} \mathrm{Cl}_{2}$ & 24 & 12 000:30:1 & 100 & 89 & 11 & 22200 & 24000 & 190 & 2.8 & 900 & 2.7 \\
\hline 20 & P3 & - & $\mathrm{CH}_{2} \mathrm{Cl}_{2}$ & 24 & 24 000:60:1 & 100 & 82 & 18 & 22200 & 23900 & 170 & 2.8 & 850 & 2.5 \\
\hline
\end{tabular}

${ }^{a}$ Refer to Table 1. ${ }^{b}$ Purification method of Px: M1 = washing with methanol; $\mathrm{M} 2=$ purification through neutral alumina using $\mathrm{CH}_{2} \mathrm{Cl}_{2}$ as eluent; $\mathrm{M} 3=$ purification through silica using pentane as eluent. ${ }^{c}$ One step $(24 \mathrm{~h})$ or two-step (cyclization and CM, $3+20 \mathrm{~h}$ ) metathesis reaction time. ${ }^{d}$ Conversion as determined by ${ }^{1} \mathrm{H}$ NMR analysis. ${ }^{e} \mathbf{D F}=\alpha, \omega-$ difunctionalized (co)polymer; $\mathbf{N F}=$ non-functionalized (co)polymer; wt $\%$ of $\mathbf{N F}=($ amount of $\mathbf{N F}$ isolated from the column / amount of crude polymer $(\mathbf{D F}+\mathbf{N F})$ before the column); wt $\%$ of $\mathbf{D F}=100-$ wt $\%$ of NF. ${ }^{f}$ Theoretical molar mass value of the (co)polymer calculated from $M_{\mathrm{n}, \text { theo }}=\left[M_{\mathbf{P x}} \times[\text { diene units in Px }]_{0} /\left([\mathrm{CTA}]_{0} \times\right.\right.$ Conv.cTA $\left.)\right]+M_{\mathrm{CTA}} \mathbf{1}$, on the basis of the formation of only DF, i.e. without taking into account any NF, with $M_{\mathbf{P 1}}=54.0 \mathrm{~g} \cdot \mathrm{mol}^{-1} ; M_{\mathbf{P} 2}=54.0 \mathrm{~g} \cdot \mathrm{mol}^{-1} ; M_{\mathbf{P} 3}=55.4 \mathrm{~g} \cdot \mathrm{mol}^{-1}$ and $M_{\text {CTA } 1}=583 \mathrm{~g} \cdot \mathrm{mol}^{-1}$. ${ }^{g}$ Experimental molar mass value determined by ${ }^{1} \mathrm{H}$ NMR analysis (refer to the Experimental Section). ${ }^{h}$ Number-average molar mass $\left(M_{\mathrm{n}, \mathrm{SEC}}\right)$ and dispersity $\left(\nexists_{\mathrm{M}}=M_{\mathrm{w}} / M_{\mathrm{n}}\right)$ values determined by SEC $v s$. polystyrene standards in THF at $30{ }^{\circ} \mathrm{C} .{ }^{i}$ Reaction performed at $60{ }^{\circ} \mathrm{C}$. 
Attempted CM depolymerization of raw P1 (i.e., technical grade as obtained from the supplier) in $\mathrm{CH}_{2} \mathrm{Cl}_{2}$ with a typical $[\mathbf{P 1}]_{0} /[\mathrm{CTA} \mathbf{1}]_{0} /[\mathbf{G 2}]_{0}$ ratio of 3000:100:1 gave no reaction (Table 2, entry 1). Wagener and al. reported that depolymerization of PBD carried out in solution is not very effective, possibly because in this case intramolecular cyclization competes with linear depolymerization. ${ }^{34,36}$ The formation of macrocycles, within a broad distribution of low-to-high molar mass compounds, from 1,4-PBD depolymerization was similarly evidenced by Sels and al. to require low concentrations. ${ }^{46}$ Similarly, Coates and Grubbs reported the highly selective and quantitative cyclization of neighboring vinyl substituents in 1,2-polydienes using metathesis catalysts. ${ }^{47}$ Correspondingly, Wagener and coauthors proposed an effective two-step, one-pot procedure: first, PBD is cyclized in solution in the presence of the catalyst, and then the solvent is removed in order to reach bulk conditions, and the CTA is next added to depolymerize the cyclic PBD (Scheme 4). ${ }^{36} \mathrm{~A}$ bulk functional depolymerization of commercial-grade PBD was attempted following this stepwise protocol: a $\mathrm{CH}_{2} \mathrm{Cl}_{2}$ solution of G2 catalyst was added onto liquid PBD (P1 or P2) and the preliminary cyclization step was carried out at $40{ }^{\circ} \mathrm{C}$ for $3 \mathrm{~h}$; then, $\mathrm{CH}_{2} \mathrm{Cl}_{2}$ was removed under vacuum and $\mathrm{CTA} 1$ was added into the reaction mixture (Scheme 4) (Table 2, entries 2-14). While the formation of difunctionalized PBD (DF) was observed from raw P1, the conversion of $\mathbf{1}$ still remained quite low and no control of molar mass values was observed (Table 2, entries 2 and 3). It is important to note that, under these same conditions, CM depolymerization of $\mathbf{P 1}$ was more efficient than that of P2. These observations suggested that bulk conditions indeed favor depolymerization of PBD as reported by Wagener and Sels, ${ }^{36,46}$ but also that impurities present in commercial grades of PBDs may prevent full conversion of $\mathbf{1}$ and a highly efficient CM. Further studies were thus next focused on functional CM depolymerization $(3+20 \mathrm{~h})$ of purified $\mathbf{P 1}$ performed in bulk at $40{ }^{\circ} \mathrm{C}$ (Scheme 4). 


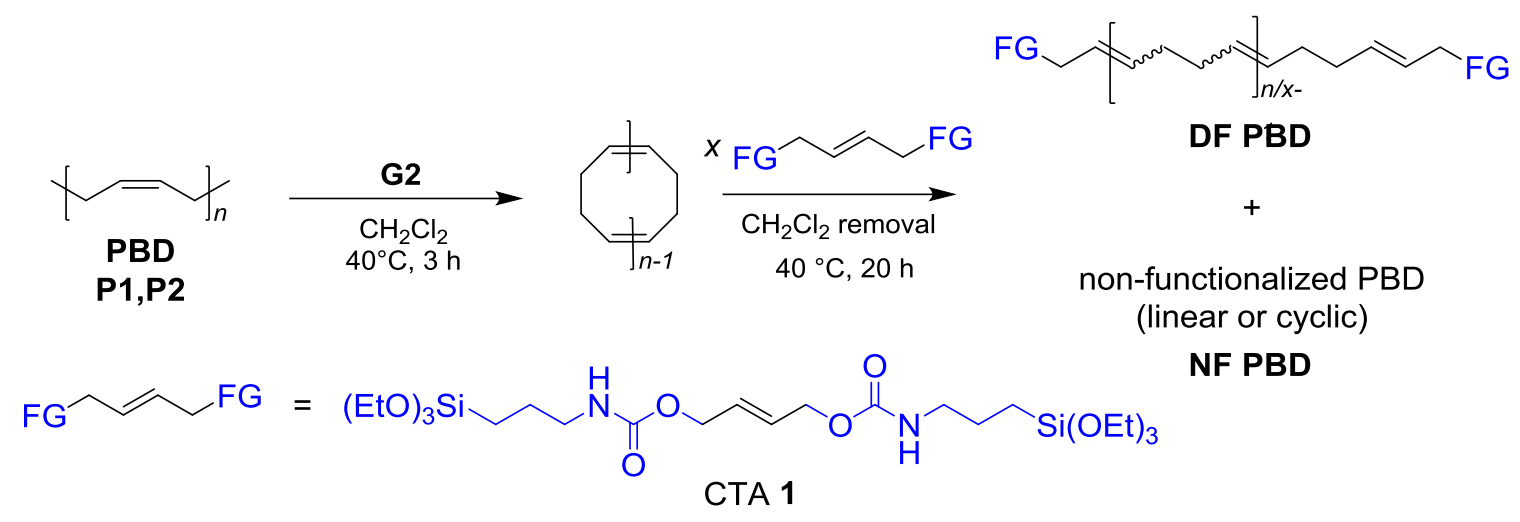

Scheme 4. Stepwise protocol for the successive cyclization and functional CM depolymerization of PBDs (P1, P2) using G2 in the presence of CTA 1, affording (non-)functionalized PBDs.

Three methods of purification of PBDs were implemented in the following experiments: washing with methanol (M1), purification through neutral alumina using $\mathrm{CH}_{2} \mathrm{Cl}_{2}$ as eluent (M2), or purification through silica using pentane as eluent (M3). ${ }^{48}$ Using P1 and P2 purified by M1, the CTA conversion increased significantly from $32 \mathrm{~mol} \%$ to $100 \mathrm{~mol} \%$ and from $12 \mathrm{~mol} \%$ to $55 \mathrm{~mol} \%$, respectively (Table 2, entries 4-5). This still supported the presence in P1 and $\mathbf{P 2}$ of some impurities that are poisonous to the metathesis catalyst, thus preventing $\mathrm{CM}$ to proceed with full effectiveness. The lower efficiency of the CM depolymerization of $\mathbf{P 2}$ compared to that of $\mathbf{P 1}$ along with a lower control of the molar mass values suggested (again) (Table 2, entries 2-3) the presence of more deleterious impurities in $\mathbf{P 2}$ than in P1. Using P1 purified by method M2 or M3 showed no difference as compared to M1, except a somewhat lower selectivity for the desired telechelic materials (vide infra) (Table 2, entries 6-7). Attempts to change the cyclization time, to add more catalyst, or to raise the reaction temperature to $60{ }^{\circ} \mathrm{C}$, did not afford a better compromise in terms of both CM efficiency and molar mass control (Table 2, entries 8-11). Increasing the cyclization reaction time from $3 \mathrm{~h}$ to $10 \mathrm{~h}$, while maintaining the $\mathrm{CM}$ reaction time to $20 \mathrm{~h}$, mostly likely induced partial deactivation of G2 catalyst, an expected feature considering the relative short lifetime of Ru metathesis catalysts. 
On the other hand, a $1 \mathrm{~h}$ cyclization time, eventually affording full conversion of $\mathbf{1}$, did not reveal beneficial either. The use of $\mathbf{P 1}$ simply washed with methanol prior to the depolymerization/cyclization/CM in $3+20 \mathrm{~h}$ steps thus remained the optimized reaction conditions.

The loadings of PBD and CTA were next increased to better assess the catalytic productivity and selectivity within an industrial context of exploitation of the process. With up to 3000 equiv. of P1 vs. G2, full conversion of CTA was observed; yet, using 25000 equiv. of P1, CM depolymerization was completely inefficient (Table 2, entries 12-14). This indicated the incomplete removal of metathesis-deleterious impurities present in PBD P1 by the M1 purification procedure.

On the other hand, interestingly, the one-pot, one-step CM depolymerization of the $\mathrm{P}(\mathrm{BD}-\mathrm{co}-\mathrm{IP})$ copolymer $\mathbf{P 3}$ proved to be effective in $\mathrm{CH}_{2} \mathrm{Cl}_{2}$ over $24 \mathrm{~h}$ at $40{ }^{\circ} \mathrm{C}$ (Scheme 4). We assume that this is possibly due to the methyl substituent of isoprene unit which prevents intramolecular cyclization usually favored in less concentrated reaction media. Remarkably, G2 catalyst showed non-optimized TON values up to 24 000, even using commercial (i.e., not purified) grade P3, with well-controlled molar mass values in terms of $M_{\mathrm{n} \text {,theo }}{ }^{49}$ and $M_{\mathrm{n}, \mathrm{NMR}}$ matching (Table 2, entries 15-20). This probably reflects the better purity of initial copolymers. Note that the molar mass values of the resulting difunctionalized copolymers as determined by SEC $\left(M_{\mathrm{n}, \mathrm{SEC}}\right)$ evidence the elution of only oligomers, thus suggesting that these $\alpha, \omega$-bis(trialkoxysilyl) $\mathrm{P}(\mathrm{BD}-\mathrm{co}$-IP) most likely remain adsorbed onto the column support.

In terms of selectivity, the amount of non-functionalized PBD or P(BD-co-IP) (NF) in the recovered crude polymers was quantified after trapping the DF polymers (from the crude $\mathbf{D F}+\mathbf{N F}$ recovered mixture) onto acidified silica, as previously reported. ${ }^{18,19}$ Note that the formation of monofunctional polydiene alongside $\mathbf{N F}$ and/or $\mathbf{D F}$, is not expected, inherently to the ROMP mechanism using a symmetrical acyclic alkene CTA, and given the initial low [CTA 
$\mathbf{1}]_{0} /[\text { vinyl }]_{0}$ ratio and the preliminary cyclization step applied (vide supra) which converts most of these vinyl moieties to generate the cyclooligomers. ${ }^{50}$ Thus, CM depolymerization of (purified) $\mathbf{P} 2$ generated much more NF PBD than that of (purified) P1 (76wt $\%$ vs. 24wt\%, Table 2, entries 4,5), in line with the above highlighted lower purity of $\mathbf{P 2}$ vs. P1 and the correspondingly less efficient CM. This confirmed the lower efficiency of the metathesis depolymerization of P2. It is yet still unclear whether this deactivation is inherent to the high content of 1,2-vinyl pendant groups (20-35\%), the maleic anhydride end-capping functions, and/or from the presence of residual deleterious impurities (which remain unidentified at this stage). A 1 h cyclization time, a twice larger amount of added catalyst, or a higher reaction temperature did not alter the chemoselectivity of the P1 CM depolymerization process $(\mathbf{N F}=$ 21wt\%; Table 2, entries 9-11). The CM depolymerization of $\mathbf{P 3}$ with a loading of 3000 equiv. vs. G2 gave only 3 wt $\%$ of NF (Table 2, entry 15). Increasing the loading of $\mathbf{P 3}$ and $\mathbf{1}$ generated more NF, yet always as a minor product ( $<18 \mathrm{wt} \%$; Table 2, entries $15-20)$. This same trend, yet significantly more pronounced $(\mathbf{N F}=23-100 \mathrm{wt} \%)$, was observed with $\mathbf{P 1}$, even affording in this case the NF PBD selectively (Table 2, entries 4,13-14).

The molar mass values as determined by $\operatorname{NMR}\left(M_{\mathrm{n}, \mathrm{NMR}}\right)$ and $\operatorname{SEC}\left(M_{\mathrm{n}, \mathrm{SEC}}\right)$ of (co)polymers generally remained in fair agreement (under optimized operating conditions, that is at full or high conversion of CTA) with the calculated values $\left(M_{\mathrm{n}, \text { theo }}\right)^{49}$ determined from the ratio of dienes units in Px-to-CTA converted (on the basis of the formation of only DF, i.e. without taking into account any NF) (Table 2). Even at high loadings of P3, telechelic polymers with fine-tuned molar mass values were readily obtained (Table 2, entries 15-20).

Keeping in mind the objective to prepare $\alpha, \omega$-bis(trialkoxysilyl) telechelic polymers that are low viscosity liquids at room temperature (so as to be readily implemented in commercial formulations), we anticipated that combining the low viscosity and low-cost of commercial PBD in CM degradation with the high efficiency and selectivity of the ROMP/CM 
of cycloolefins may offer an overall valuable approach. Indeed, copolymers based on cyclooctene/norbornene derivatives were identified as better low viscosity liquids in comparison to the related poly(cyclooctene) homopolymers. ${ }^{20}$ To our knowledge, no example of a tandem one-pot CM depolymerization-ROMP/CM of a cycloolefin experiment has been reported (Scheme 3). 1,5,9-Cyclododecatriene (CDT) and norbornene (NB) were chosen as comonomers in the present study due to their wide industrial availability. Thus, the CM depolymerization-functional ROMP/CM of P1 with CDT or NB was next investigated using G2 in the presence of CTA 1 at $40{ }^{\circ} \mathrm{C}$ in $\mathrm{CH}_{2} \mathrm{Cl}_{2}$ (Scheme 3) The most relevant results are reported in Table 3 . 
Table 3. Tandem CM depolymerization-functional ROMP/CM of PBD (P1) with CDT or NB using catalyst G2 in the presence of CTA 1 at $40{ }^{\circ} \mathrm{C}$ in $\mathrm{CH}_{2} \mathrm{Cl}_{2}$.

\begin{tabular}{|c|c|c|c|c|c|c|c|c|c|c|c|c|c|}
\hline \multirow[b]{2}{*}{ Entry } & \multirow[b]{2}{*}{ Monomer } & \multirow{2}{*}{$\begin{array}{c}{[\mathbf{P 1}]_{0}{ }^{a}} \\
\text { (equiv. } \\
\text { BD) }\end{array}$} & \multirow{2}{*}{$\begin{array}{c}{[\text { Monomer }]_{0}{ }^{b}} \\
\text { (equiv.) }\end{array}$} & \multirow[b]{2}{*}{$\begin{array}{l}{[\text { CTA 1 }]_{0}} \\
\text { (equiv.) }\end{array}$} & \multirow[b]{2}{*}{$\begin{array}{l}{[\mathbf{G 2}]_{0}} \\
\text { (equiv.) }\end{array}$} & \multirow{2}{*}{$\begin{array}{c}\mathbf{D F}^{c} \\
(\mathrm{wt} \%)\end{array}$} & \multirow{2}{*}{$\begin{array}{l}\mathbf{N F}^{c} \\
(\mathrm{wt} \%)\end{array}$} & \multicolumn{4}{|c|}{ DF } & \multicolumn{2}{|c|}{ NF } \\
\hline & & & & & & & & $\begin{array}{c}M_{\mathrm{n}, \text { theo }}{ }^{d} \\
\left(\mathrm{~g} \cdot \mathrm{mol}^{-1}\right)\end{array}$ & $\begin{array}{l}M_{\mathrm{n}, \mathrm{NMR}}{ }^{e} \\
\left(\mathrm{~g} \cdot \mathrm{mol}^{-1}\right)\end{array}$ & $\begin{array}{c}M_{\mathrm{n}, \mathrm{SEC}}{ }^{f} \\
\left(\mathrm{~g} \cdot \mathrm{mol}^{-1}\right)\end{array}$ & $\bigoplus_{M}^{f}$ & $\begin{array}{c}M_{\mathrm{n}, \mathrm{SEC}}{ }^{f} \\
\left(\mathrm{~g} \cdot \mathrm{mol}^{-1}\right)\end{array}$ & $\bigoplus_{M}{ }^{f}$ \\
\hline 2 & $\mathrm{CDT}$ & 1000 & 1000 & 50 & 1 & 75 & 25 & 4300 & 4300 & 6700 & 1.7 & 6500 & 1.3 \\
\hline 3 & CDT & 1000 & 1000 & 15 & 1 & 46 & 54 & 14900 & 14100 & 9900 & 4.0 & 9900 & 3.6 \\
\hline 6 & NB & 1000 & 1000 & 50 & 1 & 71 & 29 & 3000 & 3000 & 7900 & 1.8 & 8500 & 1.4 \\
\hline 7 & NB & 1000 & 1000 & 10 & 1 & 41 & 59 & 14900 & 14700 & 10100 & 3.0 & 10400 & 3.0 \\
\hline
\end{tabular}

${ }^{a}$ P1 washed with methanol. ${ }^{b} \mathrm{CDT}$ and NB were distilled over $\mathrm{CaH}_{2}$ prior to use; in all cases, quantitative conversion of monomers and CTA were observed by ${ }^{1} \mathrm{H}$ NMR analysis. ${ }^{c} \mathbf{D F}=\alpha, \omega$-difunctionalized copolymer; $\mathbf{N F}=$ non-functionalized copolymer; $w \mathrm{t} \%$ of $\mathbf{N F}=$ (amount of $\mathbf{N F}$ isolated from the column/amount of crude polymer $(\mathbf{D F}$ $+\mathbf{N F})$ before the column $)$; $\mathrm{wt} \%$ of $(\mathbf{D F})=100-\mathrm{wt} \%$ of NF. ${ }^{d}$ Theoretical molar mass value of the copolymer calculated from $M_{\mathrm{n}, \mathrm{theo}}=\left(M_{\mathbf{P} 1} \times[\mathrm{diene} \text { units in P1 }]_{0}+M_{\text {monomer }}\right.$ $\left.\times[\text { monomer }]_{0}\right) /\left([\mathrm{CTA}]_{0} \times\right.$ Conv. $\left._{\text {CTA }}\right)+M_{\mathbf{C T A}}$, on the basis of the formation of only $\mathbf{D F}$, i.e. without taking into account any NF. ${ }^{e}$ Experimental molar mass value determined by ${ }^{1} \mathrm{H}$ NMR analysis (refer to the Experimental Section). ${ }^{f}$ Number-average molar mass $\left(M_{\mathrm{n}, \mathrm{SEC}}\right)$ and dispersity $\left(D_{\mathrm{M}}=M_{\mathrm{w}} / M_{\mathrm{n}}\right)$ values determined by SEC $v s$. polystyrene standards in THF at $30^{\circ} \mathrm{C}$. 
The formation of liquid $\alpha, \omega$-bis(trialkoxysilyl) telechelic $\mathrm{P}(\mathrm{BD}-c o-\mathrm{CDT})$ and $\mathrm{P}(\mathrm{BD}-c o-$ NB) was observed with $[\mathbf{P 1}]_{0} /[\text { monomer }]_{0} /[\text { CTA } 1]_{0} /[\mathbf{G 2}]_{0}=1000: 1000: 10,15,50: 1$. The conversion of the monomers and CTA was quantitative in all cases. The selectivity towards DF copolymers was, regardless of the added cycloolefin monomer, similar to that observed for the CM depolymerization of PBD alone (ca. 75wt\%, Tables 2, 3).

Structure of $\alpha, \omega$-bis(trialkoxysilyl) telechelic (co)polydienes. The ${ }^{1} \mathrm{H}$ and ${ }^{13} \mathrm{C}\left\{{ }^{1} \mathrm{H}\right\} \mathrm{NMR}$ spectra of a representative crude material prepared using $[\mathbf{P 1}]_{0} /[\mathrm{CTA} \mathbf{1}]_{0} /[\mathbf{G 2}]_{0}=3000: 100: 1$ (Table 2, entry 9) are illustrated in Figures 1 and 2, respectively. The ${ }^{1} \mathrm{H}$ NMR spectrum showed, besides the main chain BD signals $\left(\delta 5.42\left(\mathrm{H}^{10}\right), 2.04\left(\mathrm{H}^{11}\right)\right)$, the presence of the characteristic resonances for DF PBD $\left(\delta 5.84\left(\mathrm{H}^{9}\right), 5.58\left(\mathrm{H}^{8}\right), 4.56\left(\mathrm{H}^{7}\right), 3.82\left(\mathrm{H}^{2}\right), 3.17\left(\mathrm{H}^{5}\right)\right.$, 1.65 $\left(\mathrm{H}^{4}\right), 0.65\left(\mathrm{H}^{3}\right)$, and $\left.1.25\left(\mathrm{H}^{1}\right)\right)$ (Figure 1). Note that the signals of NF are identical to those of the repeating BD unit in DF polymer $\left(\mathrm{H}^{10}\right.$ and $\left.\mathrm{H}^{11}\right)$, i.e. there is no characteristic hydrogen signal of NF to differentiate it from DF. Unsurprisingly, isomerization of internal $\mathrm{C}=\mathrm{C}$ double bonds in the polymer backbone was also observed $\left(\mathrm{H}^{12}\right.$ and $\mathrm{H}^{13} ; \delta 5.66 \mathrm{ppm}$ and $1.41 \mathrm{ppm}$, in red). Correspondingly, the ${ }^{13} \mathrm{C}\left\{{ }^{1} \mathrm{H}\right\}$ NMR spectrum confirmed the presence of DF and/or NF ( $\delta$ 156.4 $\left(C^{6}\right), 135.6\left(C^{8}\right), 124.4\left(C^{9}\right), 65.4\left(C^{7}\right), 58.4\left(C^{2}\right), 43.4\left(C^{5}\right), 27.4\left(C^{4}\right), 18.3\left(C^{1}\right)$ and 7.6 $\left.\left(\mathrm{C}^{3}\right)\right)$, and of isomerization of internal $\mathrm{C}=\mathrm{C}$ bonds $\left(\delta 126.8\left(\mathrm{C}^{12}\right)\right.$ and $24.9\left(\mathrm{C}^{13}\right) \mathrm{ppm}$, in red $)$ (Figure 2). All other (co)polymers prepared from $\mathbf{P 2}$ and $\mathbf{P 3}$ were similarly characterized by NMR (Figures S2-S3). 


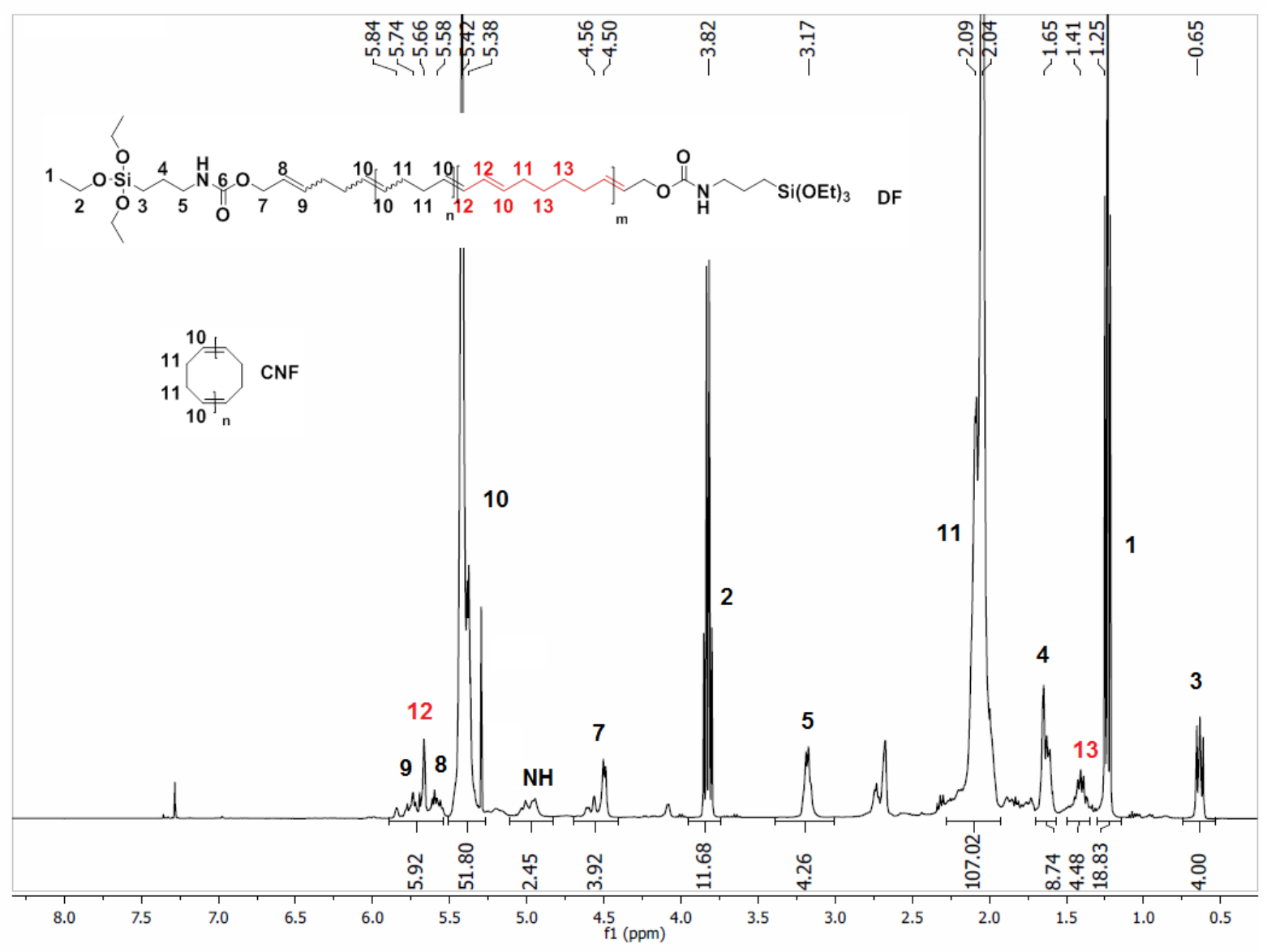

Figure 1. ${ }^{1} \mathrm{H} \mathrm{NMR}$ spectrum (400 $\mathrm{MHz}, \mathrm{CDCl}_{3}, 23{ }^{\circ} \mathrm{C}$ ) of a crude $\alpha, \omega$-bis(trialkoxysilyl) telechelic PBD sample prepared by CM depolymerization of PBD (P1) using G2 in the presence of CTA 1 (Table 2, entry 9). 


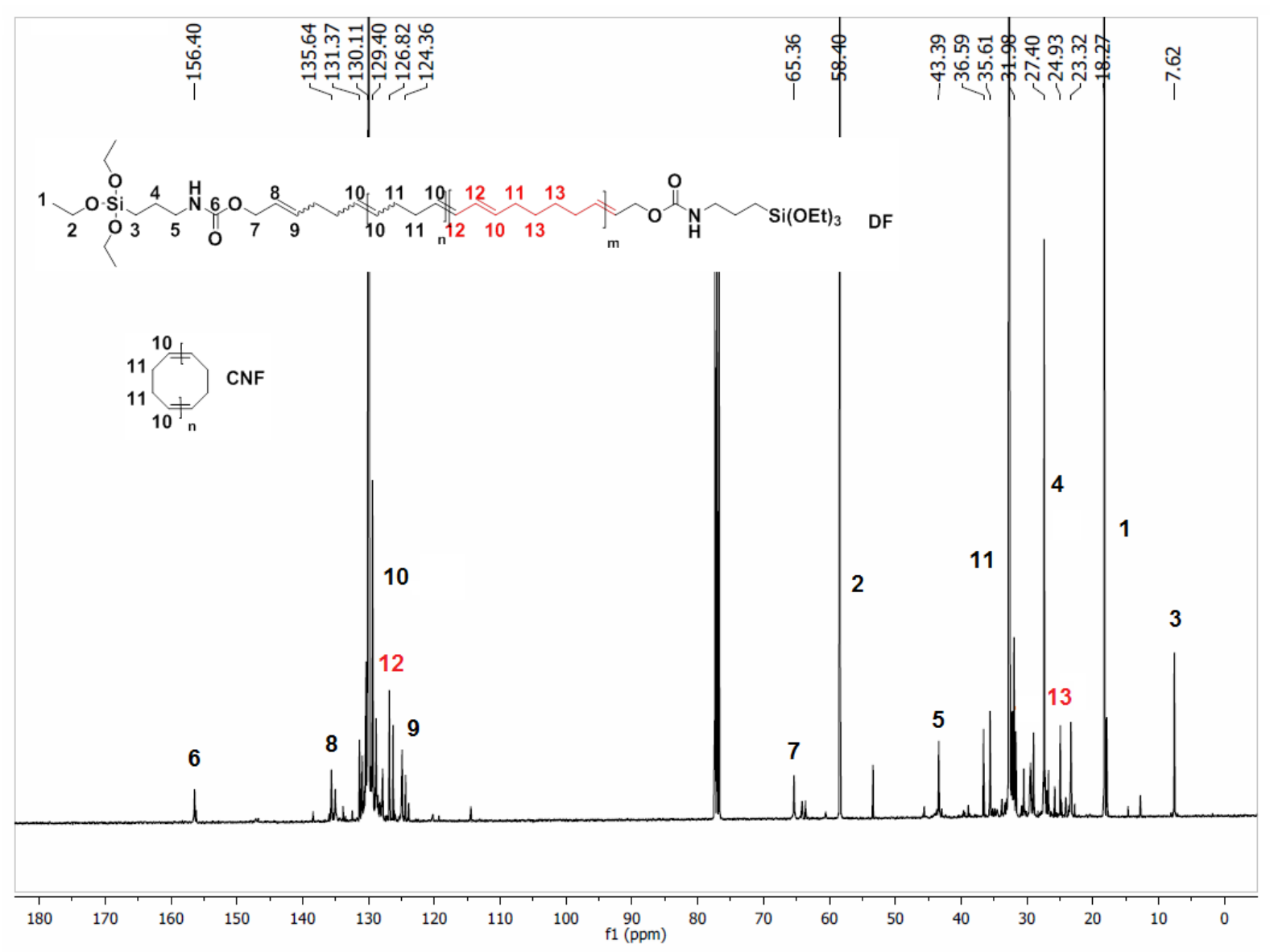

Figure 2. ${ }^{13} \mathrm{C}\left\{{ }^{1} \mathrm{H}\right\} \mathrm{NMR}\left(100 \mathrm{MHz}, \mathrm{CDCl}_{3}, 23{ }^{\circ} \mathrm{C}\right)$ of a crude $\alpha, \omega$-bis(trialkoxysilyl) telechelic PBD sample prepared by the CM depolymerization of PBD (P1) using G2 in the presence of CTA 1 (Table 2, entry 9).

The presence of DF PBD was further confirmed by MALDI-ToF mass spectrometry. Analyses were performed using a sodium salt as cationization agent, thereby enabling the easy ionization of polymers featuring heteroatoms (as DF), yet precluding the observation of the (heteroatom-free) polymers containing only $\mathrm{C}=\mathrm{C}$ bonds (as in NF). One main population was observed with a repeating unit of $54 \mathrm{~g} \cdot \mathrm{mol}^{-1}$, corresponding to $\alpha, \omega$-bis(trialkoxysilyl) difunctionalized PBD DF (with e.g. $m / z_{\text {experimental }}=m / z_{\text {simulated }}=713.4$ g. $\mathrm{mol}^{-1}$ for $n=2$; Figure 3). As anticipated from the use of a symmetric difunctional CTA and cyclo-oligo/polydienes (vide supra), no significant signal corresponding to a population of monfunctionalized macromolecules was observed. 


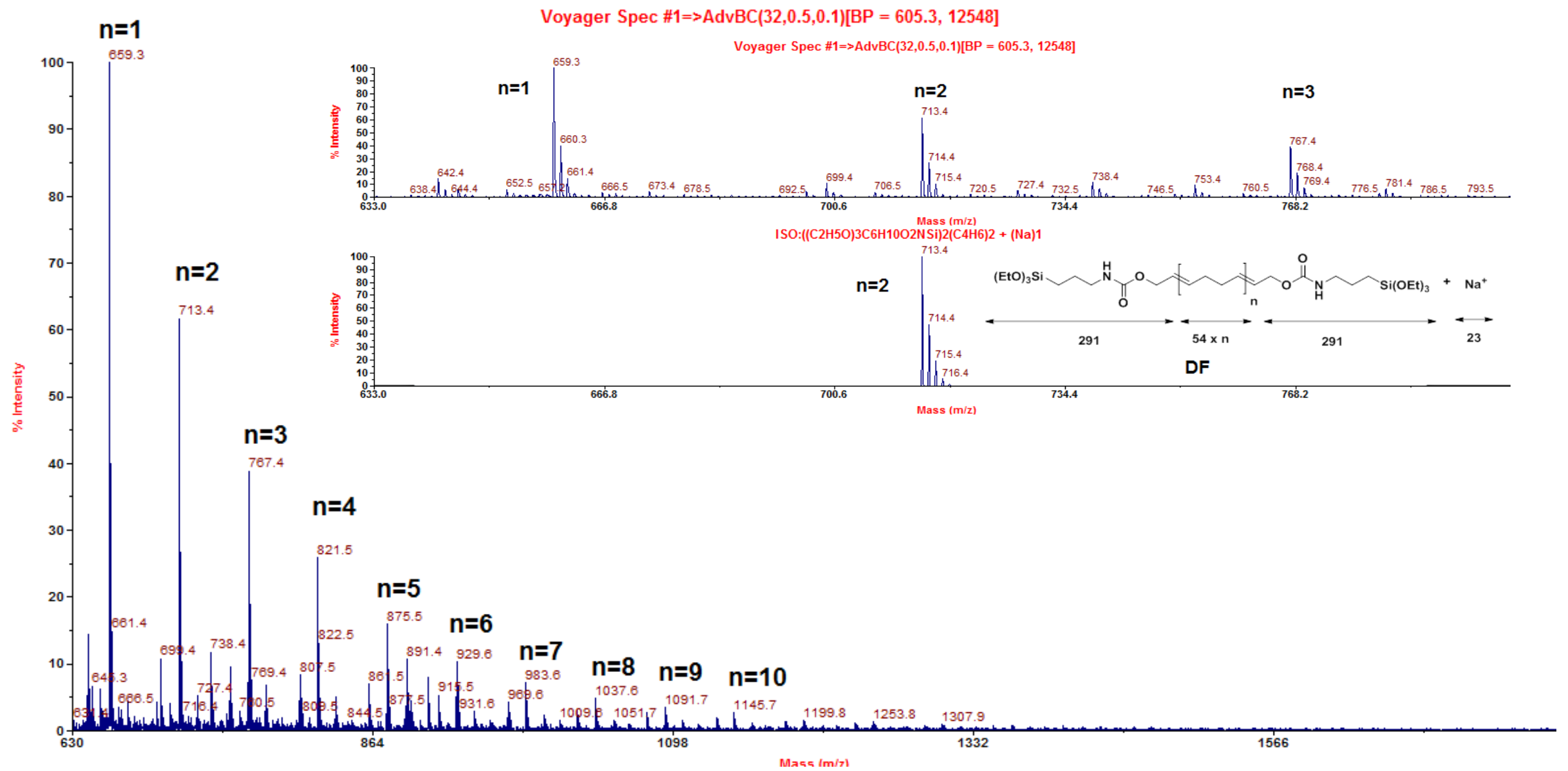

Figure 3. MALDI-ToF mass spectrum (DCTB matrix, NaI ionization salt) of a crude sample prepared by the CM depolymerization of PBD (P1) using $\mathbf{G 2}$ in the presence of CTA 1 (Table 2, entry 9), showing DF PBD; see top zoomed region and the corresponding bottom simulation for $n=$ 2. 
The chemoselectivity of this tandem metathesis reaction was further assessed through HMBC NMR analysis of the resulting material. Considering a typical HMBC spectrum of a $\mathrm{P}(\mathrm{BD}-\mathrm{co}-\mathrm{NB})$ copolymer prepared from $[\mathbf{P 1}]_{0} /[\mathrm{NB}]_{0} /[\mathbf{1}]_{0} /[\mathbf{G} 2]_{0}=1000: 1000: 50: 1$ (Table 3, entry 6), presented in Figure 4, if BD is the monomeric unit adjacent to the end-capping group of the polymer chain, $\mathrm{CH}=\mathrm{CH} \mathrm{H}^{8}$ and $\mathrm{H}^{9}$ should display correlations with the $\mathrm{BD}$ methylene $\mathrm{C}^{15}$ (positive signals on the DEPT spectrum); on the other hand, if NB is the monomeric unit adjacent to the end-capping group of the polymer chain, $\mathrm{H}^{8}$ and $\mathrm{H}^{9}$ should then exhibit correlations with the NB methine $\mathrm{C}^{12}$ (negative signals on the DEPT spectrum). The observed correlation signals between $\mathrm{H}^{8}, \mathrm{H}^{9}$ and $\mathrm{C}^{15}\left(\mathrm{CH}_{2}\right.$ on $\mathrm{BD}$ units) and not with $\mathrm{C}^{12}(\mathrm{CH}$ on $\mathrm{NB}$ units) revealed that $\mathrm{BD}$ is the only monomeric unit adjacent to the trialkoxysilyl end-capping group of the polymer chain. This indicates that NB units do not react with the CTA, and we assume that this most likely arises from their higher steric hindrance as compared to BD units. Hence, the selectivity of this tandem CM depolymerization-ROMP/CM of P1 with NB was similar to that of a simple CM depolymerization of P1. 


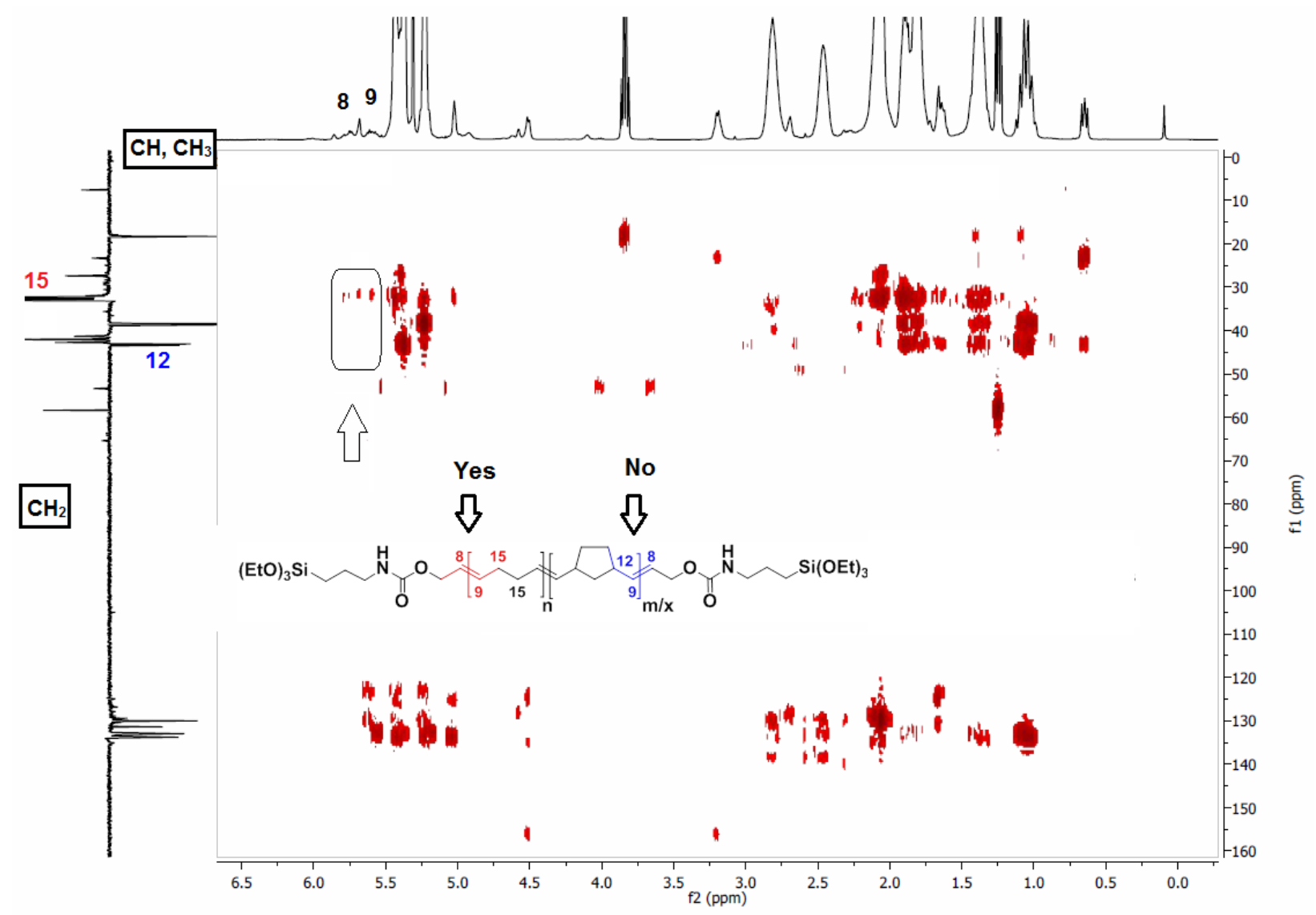

Figure 4. ${ }^{1} \mathrm{H}_{-}{ }^{13} \mathrm{C}$ (DEPT) HMBC NMR spectrum (400 $\mathrm{MHz}, \mathrm{CDCl}_{3}, 23{ }^{\circ} \mathrm{C}$ ) of a crude $\alpha, \omega$ bis(trialkoxysilyl) telechelic copolymer $\mathrm{P}(\mathrm{BD}-\mathrm{co}-\mathrm{NB})$ prepared by tandem $\mathrm{CM}$ depolymerization of PBD (P1) and ROMP/CM of NB using G2 in the presence of CTA 1 (Table 3, entry 6; the 2D spectrum with assignments of all signals is provided in Figure S4).

\section{Viscosity and rheological properties of $\alpha, \omega$-bis(trialkoxysilyl) telechelic P(CDT-co-BD)} and $\mathrm{P}(\mathrm{BD}-\mathrm{co}-\mathrm{NB})$. The viscosity properties of the telechelic $\mathrm{PBD}, \mathrm{P}(\mathrm{BD}-\mathrm{co}-\mathrm{CDT})$ and $\mathrm{P}(\mathrm{BD}-$ co-NB) materials of similar molar mass value prepared by tandem CM depolymerization of PBD (P1) and ROMP/CM of NB using $\mathbf{G 2}$ in the presence of CTA 1 were preliminarily investigated at room temperature in simple shear flows (Table 4, Figures S5, S6). The rheological behavior of both type of copolymers was actually shear thinning. The viscosity of $\mathrm{P}(\mathrm{BD}-\mathrm{co}-\mathrm{CDT})$ was ca. 40 times larger than that of $\mathrm{P}(\mathrm{BD}-\mathrm{co}-\mathrm{NB})$ (Table 4). This is probably intrinsic to the nature of the copolymer featuring CDT rather than NB (branched) repeating units. CDT units synthesized by ROMP have high trans configuration, as favored by 
metathesis. ${ }^{51,52}$ These multiple trans double bonds, as in semicrystalline trans-enriched 1,4$\mathrm{PBD},{ }^{53,54}$ impart some linearity/rigidity to the polymer chains of $\mathrm{P}(\mathrm{BD}-\mathrm{co}-\mathrm{CDT})$ derived from P1 (a PBD 75mol\% enriched in trans units; Table 1), enabling segments of the macromolecules to align into crystalline domains within the material. On the other hand, NB units may cause bending of the polyene chain, preventing macromolecules from aligning into crystalline regions, thus resulting in larger amorphous regions and thus in a more liquid-like material. In comparison, the copolymers $\alpha, \omega$-bis(trialkoxysilyl) telechelic $\mathrm{P}(\mathrm{BD}-\mathrm{co}-\mathrm{IP})$ synthesized by $\mathrm{CM}$ depolymerization of $\mathbf{P 3}$ using CTA 1 have a very low viscosity regardless of the molar mass. We assume that this most likely results from the presence of oligomers (as evidenced by SEC analysis; Table 3) which can act as plasticizers, thus lowering the viscosity. 
Table 4. Newtonian viscosity and rheological properties of $\alpha, \omega$-bis(trialkoxysilyl) telechelic P(BD-co-CDT), $\mathrm{P}(\mathrm{BD}-c o-\mathrm{NB})$ and $\mathrm{P}(\mathrm{BD}-c o-\mathrm{IP})$.

\begin{tabular}{|c|c|c|c|c|c|c|c|c|c|c|c|}
\hline Entry & (Co)polydiene & Monomer & $\begin{array}{l}\text { Difunctional } \\
\text { (co)polymer }{ }^{a}\end{array}$ & $\begin{array}{c}{[\mathbf{P x}]_{0} /} \\
{[\text { monomer }]_{0} /} \\
{[\text { CTA } 1]_{0} /[\mathbf{G 2}]_{0}{ }^{b}}\end{array}$ & $\begin{array}{c}\mathbf{D F}^{c} \\
(\mathrm{wt} \%)\end{array}$ & $\begin{array}{l}\mathbf{N F}^{c} \\
(\mathrm{wt} \%)\end{array}$ & $\begin{array}{c}M_{\mathrm{n}, \mathrm{NMR}}{ }^{2} \\
\left(\mathrm{~g} \cdot \mathrm{mol}^{-1}\right)\end{array}$ & $\begin{array}{c}M_{\mathrm{n}, \mathrm{SEC}}{ }^{e} \\
\left(\mathrm{~g} \cdot \mathrm{mol}^{-1}\right)\end{array}$ & $\bigoplus_{M}^{e}$ & $\begin{array}{c}\text { Newtonian } \\
\text { viscosity } \\
\text { at } 25^{\circ} \mathrm{C}^{f} \\
(\text { Pa.s })\end{array}$ & $\begin{array}{c}\text { Rheological } \\
\text { behavior } \\
\text { at } 25^{\circ} \mathrm{C}^{f}\end{array}$ \\
\hline 2 & $\mathbf{P 1}$ & NB & $\mathrm{P}(\mathrm{BD}-c o-\mathrm{NB})$ & 1000: 000:10:1 & 41 & 59 & 14700 & 10100 & 3.0 & 658 & Shear thinning \\
\hline 3 & P3 & - & $\mathrm{P}(\mathrm{BD}-c o-\mathrm{IP})$ & 3000:0:100:1 & 97 & 3 & 1500 & 400 & 2.1 & 30 & Newtonian \\
\hline
\end{tabular}

${ }^{a}$ Refer to Tables 2,3. ${ }^{b}$ In all cases, quantitative conversion of monomers and CTA were observed by ${ }^{1} \mathrm{H}$ NMR analysis. ${ }^{c} \mathbf{D F}=\alpha, \omega$-difunctionalized copolymer; $\mathbf{N F}=$ nonfunctionalized copolymer; $\mathrm{wt} \%$ of $\mathbf{N F}=$ (amount of $\mathbf{N F}$ isolated from the column/amount of crude polymer $(\mathbf{D F}+\mathbf{N F})$ before the column); wt $\%$ of $(\mathbf{D F})=100-\mathrm{wt} \%$ of $\mathbf{N F}$. ${ }^{d}$ Experimental molar mass value determined by ${ }^{1} \mathrm{H}$ NMR analysis (refer to the Experimental Section). ${ }^{e}$ Number-average molar mass $\left(M_{\mathrm{n}, \mathrm{SEC}}\right)$ and dispersity $\left(\bigoplus_{\mathrm{M}}=M_{\mathrm{w}} / M_{\mathrm{n}}\right)$ values determined by SEC $v$ s. polystyrene standards in THF at $30{ }^{\circ} \mathrm{C} .{ }^{f}$ Measured using ARES G2 (TA instrument) at $25{ }^{\circ} \mathrm{C}$; uncertainty $= \pm 5 \%$. 


\section{Concluding remarks}

The functional $\mathrm{CM}$ depolymerization of commercial, liquid low molar mass (co)polydienes $\mathrm{PBD}$ and $\mathrm{P}(\mathrm{BD}-\mathrm{co}-\mathrm{IP})$ (P1-P3), using a ruthenium catalyst and a symmetrical bis(trialkoxysilyl) difunctional olefin as chain-transfer agent efficiently affords liquid, lowviscosity $\alpha, \omega$-bis(trialkoxysilyl) telechelic (co)polyolefins. The industrial advantage of this metathesis method lies in the low cost and easier handling of PBD and P(BD-co-IP) compared to usual ROMP/CM of cycloolefins. ${ }^{18-20}$ Under optimized operating conditions (purification of $\mathbf{P 1}$ and $\mathbf{P 2}$, bulk conditions for $\mathbf{P 1}$ and $\mathbf{P 2}, \mathrm{CH}_{2} \mathrm{Cl}_{2}$ solutions for $\mathbf{P 3}, 40{ }^{\circ} \mathrm{C}$ ), and at reasonably low P1-P3 loadings (up to ca. 3000 equiv. with P1, P2 and up to 24000 equiv. with P3), $\alpha, \omega-$ bis(trialkoxysilyl) difunctionalized (DF) (co)polymers were formed as the major product along with some non-functionalized (NF) (co)polyolefin. The largest catalytic productivity (TON = 24 000; not optimized) and selectivity (82wt\% of DF) were simultaneously achieved using an unpurified P(BD-co-IP) copolymer from Kuraray (LIR390, P3).

The tandem CM depolymerization of PBD and functional ROMP/CM of CDT or NB using a bis(trialkoxysilyl) difunctional CTA is an original way, to our knowledge not reported in the literature, to generate liquid $\alpha, \omega$-bis(trialkoxysilyl) telechelic copolyolefins. Liquid low viscosity bis(trialkoxysilyl) telechelic $\mathrm{P}(\mathrm{BD}-\mathrm{co}-\mathrm{CDT})$ and $\mathrm{P}(\mathrm{BD}-\mathrm{co}-\mathrm{NB})$ were thus synthesized while the selectivity towards DF copolymers remained high at ca. $75 \mathrm{wt} \%$.

The high productivity and selectivity reached in the generation of liquid $\alpha, \omega$-bis(trialkoxysilyl) (co)polyolefins are compatible with an industrial implementation. Formulation and adhesive applications of these adhesive polymer precursors will be reported in due course. 


\section{Experimental Section}

Materials. All catalytic experiments were performed under inert atmosphere (argon, $<3 \mathrm{ppm}$ $\mathrm{O}_{2}$ ) using standard Schlenk line and glove box techniques. Norbornene (NB), cyclododecatriene (CDT) and $\mathrm{CH}_{2} \mathrm{Cl}_{2}$ (stabilized with amylene) were dried and distilled over $\mathrm{CaH}_{2}$ before use. Grubbs' $2^{\text {nd }}$ generation catalyst (G2) was purchased from Sigma-Aldrich and used as received. Polyvest ${ }^{\circledR} 10$ (P1), Ricon®130MA8 (P2), and LIR390 (P3) were purchased from Evonik, Cray Valley, and Kuraray, respectively (Table 1). CTA 1 was synthesized according to the reported literature procedure. ${ }^{19}$

Instrumentation and measurements. ${ }^{1} \mathrm{H}(500,400 \mathrm{MHz})$ and ${ }^{13} \mathrm{C}\left\{{ }^{1} \mathrm{H}\right\}(125,100 \mathrm{MHz}) \mathrm{NMR}$ spectra were recorded on Bruker Avance AM 500 and AM 400 spectrometers at $23{ }^{\circ} \mathrm{C}$ in $\mathrm{CDCl}_{3}$. Chemical shifts $(\delta)$ are reported in ppm and were referenced internally relative to tetramethylsilane $(\delta 0 \mathrm{ppm})$ using the residual ${ }^{1} \mathrm{H}$ and ${ }^{13} \mathrm{C}$ solvent resonances. A relaxation delay of $1 \mathrm{~s}$ and $1.5 \mathrm{~s}$ was used during the acquisition to afford "quantitative" ${ }^{1} \mathrm{H}$ and ${ }^{13} \mathrm{C}\left\{{ }^{1} \mathrm{H}\right\} \mathrm{NMR}$ spectra, respectively.

The molar mass values of the polymers samples were determined by ${ }^{1} \mathrm{H}$ NMR analysis in $\mathrm{CDCl}_{3}\left(M_{\mathrm{n}, \mathrm{NMR}}\right)$ from the integral ratio of the signals of hydrogens on the functional group (typically $\left.\delta 0.65\left(\mathrm{H}^{3}\right)\right)$ to internal olefin hydrogens $\left(\delta 5.42\left(\mathrm{H}^{10}\right)\right)$ (see Figure 1$)$.

The average molar mass $\left(M_{\mathrm{n}, \mathrm{SEC}}\right)$ and dispersity $\left(\bigoplus_{\mathrm{M}}=M_{\mathrm{w}} / M_{\mathrm{n}}\right)$ values were determined by size exclusion chromatography $(\mathrm{SEC})$ in THF at $30{ }^{\circ} \mathrm{C}\left(\right.$ flow rate $=1.0 \mathrm{~mL} \cdot \mathrm{min}^{-1}$ ) on a Polymer Laboratories PL50 apparatus equipped with a refractive index detector and a set of two ResiPore PLgel $3 \mu \mathrm{m}$ MIXED-E $300 \times 7.5 \mathrm{~mm}$ columns. The polymer samples were dissolved in THF $\left(2 \mathrm{mg} \cdot \mathrm{mL}^{-1}\right)$. All elution curves were calibrated with 12 monodisperse polystyrene standards $\left(M_{\mathrm{n}}\right.$ range $\left.=580-380000 \mathrm{~g} \cdot \mathrm{mol}^{-1}\right) \cdot M_{\mathrm{n}, \mathrm{SEC}}$ values of polymers were uncorrected for their possible difference in hydrodynamic volume vs. polystyrene. 
MALDI-ToF mass spectra were recorded at the CESAMO (Bordeaux, France) on a Voyager mass spectrometer (Applied Biosystems) equipped with a pulsed $\mathrm{N}_{2}$ laser source (337 $\mathrm{nm}, 4 \mathrm{~ns}$ pulse width) and a time-delayed extracted ion source. Spectra were recorded in the positive-ion mode using the reflectron mode and with an accelerating voltage of $20 \mathrm{kV}$. A freshly prepared solution of the polymer sample in THF (HPLC grade, $10 \mathrm{mg} \cdot \mathrm{mL}^{-1}$ ), a saturated solution of trans-2-[3-(4-tert-butylphenyl)-2-methyl-2-propenylidene]malononitrile (DCTB, $10 \mathrm{mg}$ ) in THF (1 mL, HPLC grade) were prepared. A MeOH solution of the cationisation agent (NaI, $10 \mathrm{mg} \cdot \mathrm{mL}^{-1}$ ) was also prepared. The solutions were combined in a 10:1:1 $\mathrm{v} / \mathrm{v}$ of matrixto-sample-to-cationisation agent. 1-2 $\mu \mathrm{L}$ of the resulting solution were deposited onto the sample target and vacuum-dried.

Apparent viscosity was measured with a ARES G2 viscosimeter, equipped with a plateplate geometry, over a shear rate range from $0 \mathrm{~s}^{-1}$ to $500 \mathrm{~s}^{-1}$. At each imposed shear rate, the apparent viscosity was determined in the steady state regime. Temperature was fixed at $25 \pm$ $0.3{ }^{\circ} \mathrm{C}$. For each sample, the viscosimetric test duration was 5 min.

Typical procedure for CM depolymerization of P1/P2 in bulk conditions. All polymerizations in bulk were performed according to the following typical procedure (Table 2, entry 2). The only differences lie in the initial concentrations $\left([\mathbf{P 1} / \mathbf{P 2}]_{0}\right.$ and $\left.[\mathrm{CTA}]_{0}\right)$. Under argon atmosphere, a Schlenk flask $(20 \mathrm{~mL})$ equipped with a magnetic stir bar was charged sequentially with dry $\mathrm{CH}_{2} \mathrm{Cl}_{2}(5.0 \mathrm{~mL})$ and $\mathrm{PBD}(0.98 \mathrm{~mL}, 0.97 \mathrm{~g}, 17.7 \mathrm{mmol})$. The resulting solution was placed at $40{ }^{\circ} \mathrm{C}$ and the cyclization was started upon addition, via a cannula, of a dry, freshly prepared $\mathrm{CH}_{2} \mathrm{Cl}_{2}$ solution $(2.0 \mathrm{~mL})$ of $\mathbf{G 2}(5.0 \mathrm{mg}, 5.3 \mu \mathrm{mol})$. After the desired reaction time (typically 3 h, not optimized), volatiles were removed under vacuum. CTA 1 (343 $\mathrm{mg}, 0.59 \mathrm{mmol}$ ) was added in the reaction medium for the $\mathrm{CM}$ to proceed. After $20 \mathrm{~h}$ (reaction time not optimized), the polymer was recovered as a brownish liquid, readily soluble in 
chloroform and THF, and insoluble in methanol (Table 2). Note that samples obtained by depolymerization of $\mathbf{P 2}$ displayed the same NMR spectra as those prepared from $\mathbf{P 1}$.

Typical procedure for $\mathrm{CM}$ depolymerization of $\mathrm{P3} / \mathrm{P1}$ in solution. All P3 CM depolymerizations in solution were performed according to the following typical procedure (Table 2, entry 15). The only differences lie in the initial concentrations ([P3 $]_{0}$ and $\left.[\mathrm{CTA}]_{0}\right)$. Under argon atmosphere, a Schlenk flask $(20 \mathrm{~mL})$ equipped with a magnetic stir bar was charged sequentially with dry $\mathrm{CH}_{2} \mathrm{Cl}_{2}(5.0 \mathrm{~mL})$ and $\mathbf{P 3}(0.98 \mathrm{~mL}, 0.97 \mathrm{~g}, 17.5 \mathrm{mmol}$ diene units). The resulting solution was placed at $40{ }^{\circ} \mathrm{C}$ and the cyclization was started upon addition, via a cannula, of a dry, freshly prepared $\mathrm{CH}_{2} \mathrm{Cl}_{2}$ solution $(2.0 \mathrm{~mL})$ of $\mathbf{G 2}(5.0 \mathrm{mg}, 5.3 \mu \mathrm{mol})$. After the desired reaction time (typically $24 \mathrm{~h}$, not optimized), volatiles were removed under vacuum. The polymer was recovered as a brownish liquid, readily soluble in chloroform and THF, and insoluble in methanol (Table 2, entries 15-20). The polymer sample was characterized by SEC, ${ }^{1} \mathrm{H}$ and ${ }^{13} \mathrm{C}\left\{{ }^{1} \mathrm{H}\right\}$ NMR (Figures S1-S3), and FTIR $\left(\mathrm{cm}^{-1}\right)$ ) $v 3356(\mathrm{~N}-\mathrm{H})$, $2915(\mathrm{C}-\mathrm{H}), 2843(\mathrm{C}-\mathrm{H}), 1726(\mathrm{C}=\mathrm{O}), 1518(\mathrm{C}-\mathrm{N}), 1437(\mathrm{C}-\mathrm{H}), 1238(\mathrm{C}-\mathrm{N}), 1165(\mathrm{C}-\mathrm{O})$; 1176 (Si-O-C); $962(\mathrm{C}-\mathrm{H}) ; 775$ (Si-O-C) (Figure S7). The CM depolymerization of P1 in $\mathrm{CH}_{2} \mathrm{Cl}_{2}$ was similarly carried out (Table 2, entry 9). The sample was characterized by ${ }^{1} \mathrm{H}$, ${ }^{13} \mathrm{C}\left\{{ }^{1} \mathrm{H}\right\}$ and DEPT NMR, and mass spectrometry (Figures $1-3$ ).

Typical procedure for tandem CM depolymerization of P1/P2 and ROMP/CM of a cycloolefin. All tandem CM depolymerization of PBD (P1 or P2) and ROMP/CM of cycloolefin (NB or CDT) were performed according to the following typical procedure (Table 3, entry 1). Under argon atmosphere, a Schlenk flask (20 mL) equipped with a magnetic stir bar was charged sequentially with dry $\mathrm{CH}_{2} \mathrm{Cl}_{2}(10.0 \mathrm{~mL}), \mathrm{PBD}(0.98 \mathrm{~mL}, 0.97 \mathrm{~g}, 17.7 \mathrm{mmol})$ and NB (1.66 g, $17.7 \mathrm{mmol})$. The resulting solution was placed at $40{ }^{\circ} \mathrm{C}$ and the cyclization was started upon addition, via a cannula, of a dry, freshly prepared $\mathrm{CH}_{2} \mathrm{Cl}_{2}$ solution $(4.0 \mathrm{~mL})$ of $\mathbf{G 2}$ (10.0 mg, $10.6 \mu \mathrm{mol})$. After $3 \mathrm{~h}$, volatiles were removed under vacuum. CTA 1 (686 mg, 1.18 
mmol) was added in the reaction medium for the $\mathrm{CM}$ to proceed. After $20 \mathrm{~h}$ (reaction time not optimized), the polymer was recovered as brown liquid, readily soluble in chloroform and THF, and insoluble in methanol (Table 3). The polymer sample was characterized by ${ }^{1} \mathrm{H}$ and ${ }^{13} \mathrm{C}\left\{{ }^{1} \mathrm{H}\right\}$ NMR (Figures S4, S5, S8, S9).

Separation of non-functionalized (NF) polymers from functionalized (DF) polymers. NF polymers were separated from crude polymers $(\mathbf{D F}+\mathbf{N F})$ by column chromatography on silica gel 60 acidified with $\mathrm{HCl}(37 \%)$ until $\mathrm{pH}<2$, using $\mathrm{CH}_{2} \mathrm{Cl}_{2}$ as eluent. Functionalized polymers (DF) thus remained grafted onto the acidified silica, while NF polymers were isolated from the eluted solution.

Electronic Supporting Information. Representative ${ }^{1} \mathrm{H}$ and ${ }^{13} \mathrm{C}$ NMR spectra, FTIR spectra, SEC traces and flow curves of polymer materials.

Acknowledgements. Financial support of this research by Bostik and Total Cies (Ph.D. grant to X.M.) is gratefully acknowledged. 


\section{Supporting Information}

for

Simple Access to Alkoxysilyl Telechelic Polyolefins as Precursors of Adhesive Materials from the Ruthenium-Catalyzed Cross-Metathesis Depolymerization of Polydienes

Xiaolu Michel, ${ }^{\mathrm{a}}$ Stéphane Fouquay, ${ }^{\mathrm{b}}$ Guillaume Michaud, ${ }^{\mathrm{c}}$ Frédéric Simon, ${ }^{\mathrm{c}}$ Jean-Michel Brusson, ${ }^{\mathrm{d}}$ Jean-François Carpentier (ORCID: 0000-0002-9160-7662), ${ }^{\mathrm{a},{ }^{*}}$ and Sophie M. Guillaume (ORCID: 0000-0003-2917-8657) ${ }^{\mathrm{a}, *}$

${ }^{a}$ University of Rennes 1, CNRS, Institut des Sciences Chimiques de Rennes (ISCR), UMR 6226, F-35042 Rennes Cedex, France

${ }^{b}$ BOSTIK S.A., F-93211 La Plaine Saint-Denis, France

${ }^{c}$ BOSTIK S.A., F-60280 Venette, France

${ }^{d}$ Total S.A., Corporate Science, F-92069 Paris La Défense Cedex, France

*Corresponding authors: jean-francois.carpentier@univ-rennes1.fr; $\underline{\text { sophie.guillaume@univ-rennes1.fr }}$ 


\section{Table of contents}

Figure S1. SEC traces of a crude $\alpha, \omega$-bis(trialkoxysilyl) telechelic copolymer prepared by CM depolymerization of $\mathrm{P}(\mathrm{BD}-\mathrm{co}-\mathrm{IP})$ (P3) using $\mathbf{G 2}$ in the presence of CTA 1 (Table 2, entry 15, blue trace) and native $\mathrm{P}(\mathrm{BD}-\mathrm{co}-\mathrm{IP})(\mathbf{P 3})$ from Kuraray (red trace).

Figure S2. ${ }^{1} \mathrm{H}$ NMR spectrum $\left(400 \mathrm{MHz}, \mathrm{CDCl}_{3}, 23{ }^{\circ} \mathrm{C}\right.$ ) of a crude $\alpha, \omega$-bis(trialkoxysilyl) telechelic $\mathrm{P}(\mathrm{BD}-$ co-IP) sample prepared by the $\mathrm{CM}$ depolymerization of $\mathbf{P 3}$ using $\mathbf{G} 2$ in the presence of CTA 1 (Table 2, entry 15).

Figure S3. ${ }^{13} \mathrm{C}\left\{{ }^{1} \mathrm{H}\right\}$ NMR $\left(100 \mathrm{MHz}, \mathrm{CDCl}_{3}, 23{ }^{\circ} \mathrm{C}\right)$ of a crude $\alpha, \omega$-bis(trialkoxysilyl) telechelic $\mathrm{P}(\mathrm{BD}-$ co-IP) sample prepared by $\mathrm{CM}$ depolymerization of $\mathbf{P 3}$ using $\mathbf{G 2}$ in the presence of CTA 1 (Table 2, entry 15).

Figure S4. ${ }^{1} \mathrm{H}_{-}{ }^{13} \mathrm{C}$ (DEPT) HMBC NMR spectrum $\left(400 \mathrm{MHz}, \mathrm{CDCl}_{3}, 23{ }^{\circ} \mathrm{C}\right)$ of a crude $\alpha, \omega$-bis(trialkoxysilyl) telechelic copolymer $\mathrm{P}(\mathrm{BD}-\mathrm{co}-\mathrm{NB})$ prepared by $\mathrm{CM}$ depolymerization of PBD (P1) and ROMP/CM of NB using $\mathbf{G 2}$ in the presence of CTA 1 (Table 3, entry 6).

Figure S5. Flow curves of $\alpha, \omega$-bis(trialkoxysilyl) telechelic copolyolefin samples prepared from CM depolymerization of PBD (P1) and ROMP of CDT and NB using catalyst $\mathbf{G} 2$ in the presence of CTA 1 (Table 4, entries 1-2).

Figure S6. Flow curves of Kuraray LIR390 (P3, blue) and copolymer samples prepared from the depolymerization of P3 using G2 and CTA 1 (Table 4, entries 3-4, red).

Figure S7. FTIR spectrum of a crude $\alpha, \omega$-bis(trialkoxysilyl) telechelic copolymer prepared by CM depolymerization of $\mathrm{P}(\mathrm{BD}-\mathrm{co}-\mathrm{IP})$ (P3) using $\mathbf{G 2}$ in the presence of CTA 1 (Table 2, entry $15)$.

Figure S8. ${ }^{1} \mathrm{H}$ NMR spectrum $\left(500 \mathrm{MHz}, \mathrm{CDCl}_{3}, 23{ }^{\circ} \mathrm{C}\right.$ ) of a crude $\alpha, \omega$-bis(trialkoxysilyl) telechelic copolymer prepared by CM depolymerization of PBD (P1) and ROMP/CM of NB coupling using G2 in the presence of CTA 1 (Table 3, entry 6). 
Figure S9. ${ }^{13} \mathrm{C}\left\{{ }^{1} \mathrm{H}\right\} \quad \mathrm{NMR}$ spectrum $\left(100 \mathrm{MHz}, \quad \mathrm{CDCl}_{3}, \quad 23{ }^{\circ} \mathrm{C}\right)$ of a crude $\alpha, \omega$-bis(trialkoxysilyl) telechelic copolymer prepared by CM depolymerization of PBD (P1) and ROMP/CM of NB coupling using $\mathbf{G 2}$ in the presence of CTA 1 (Table 3, entry 6). 


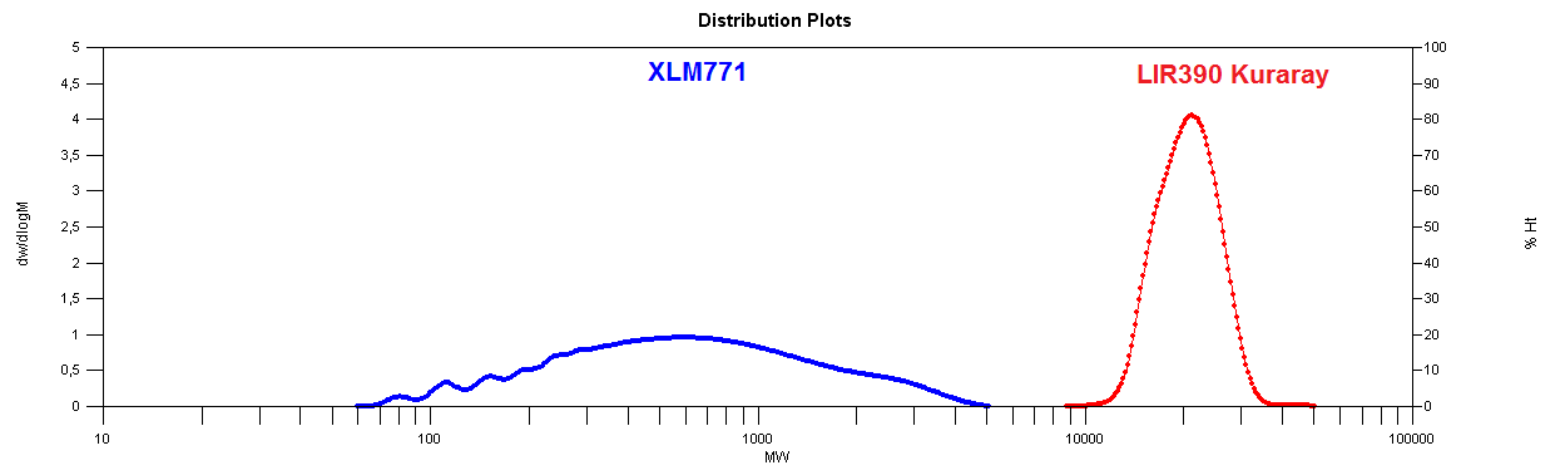

Figure S1. SEC traces of a crude $\alpha, \omega$-bis(trialkoxysilyl) telechelic copolymer prepared by CM depolymerization of $\mathrm{P}(\mathrm{BD}-\mathrm{co}-\mathrm{IP})$ (P3) using $\mathbf{G} 2$ in the presence of CTA 1 (Table 2, entry 15, blue trace) and native $\mathrm{P}(\mathrm{BD}-\mathrm{co}-\mathrm{IP})(\mathbf{P 3})$ from Kuraray (red trace).

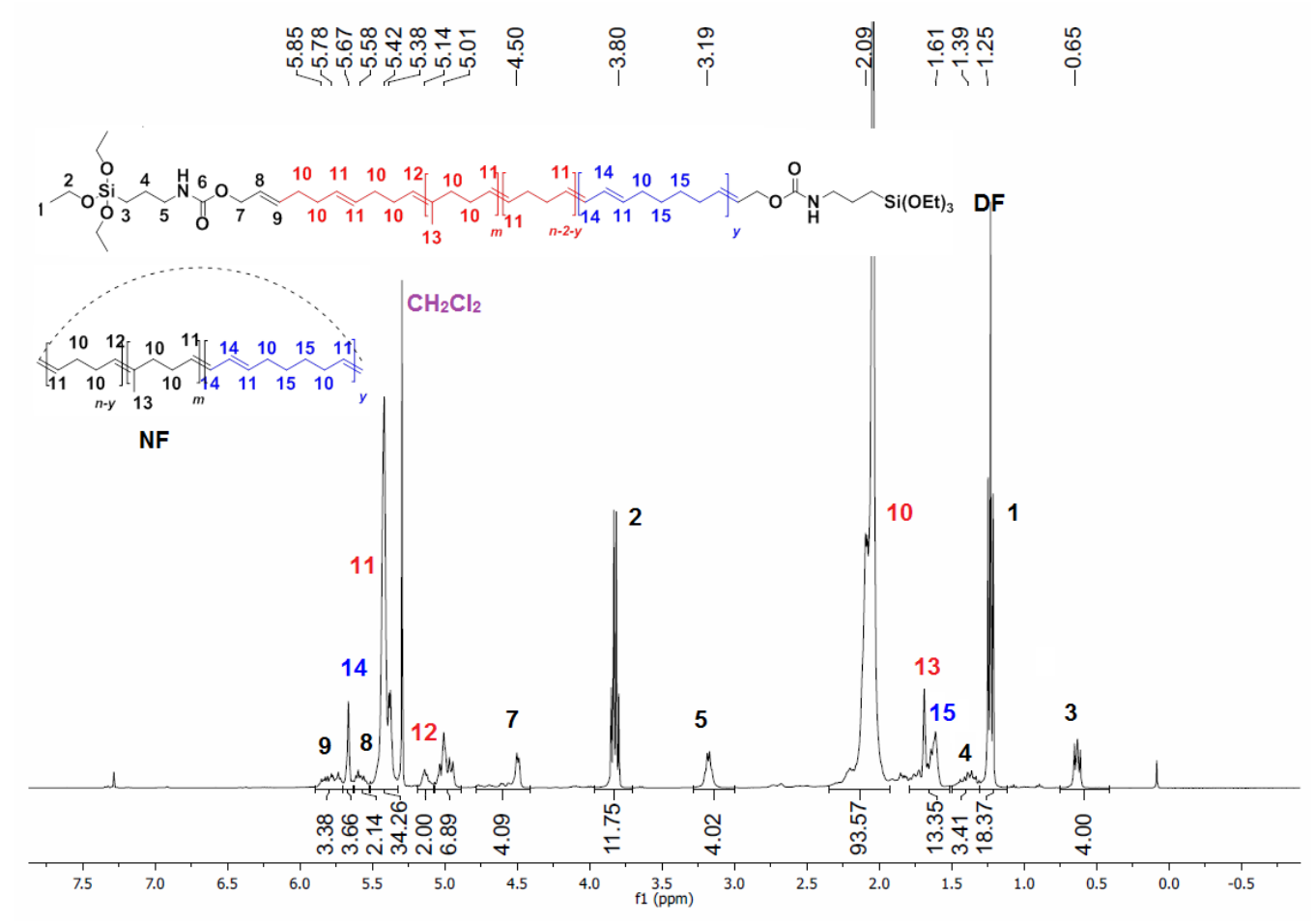

Figure S2. ${ }^{1} \mathrm{H}$ NMR spectrum $\left(400 \mathrm{MHz}, \mathrm{CDCl}_{3}, 23{ }^{\circ} \mathrm{C}\right)$ of a crude $\alpha, \omega$-bis(trialkoxysilyl) telechelic $\mathrm{P}(\mathrm{BD}-\mathrm{co}-\mathrm{IP})$ sample prepared by $\mathrm{CM}$ depolymerization of $\mathbf{P 3}$ using $\mathbf{G 2}$ in the presence of CTA 1 (Table 2, entry 15). 


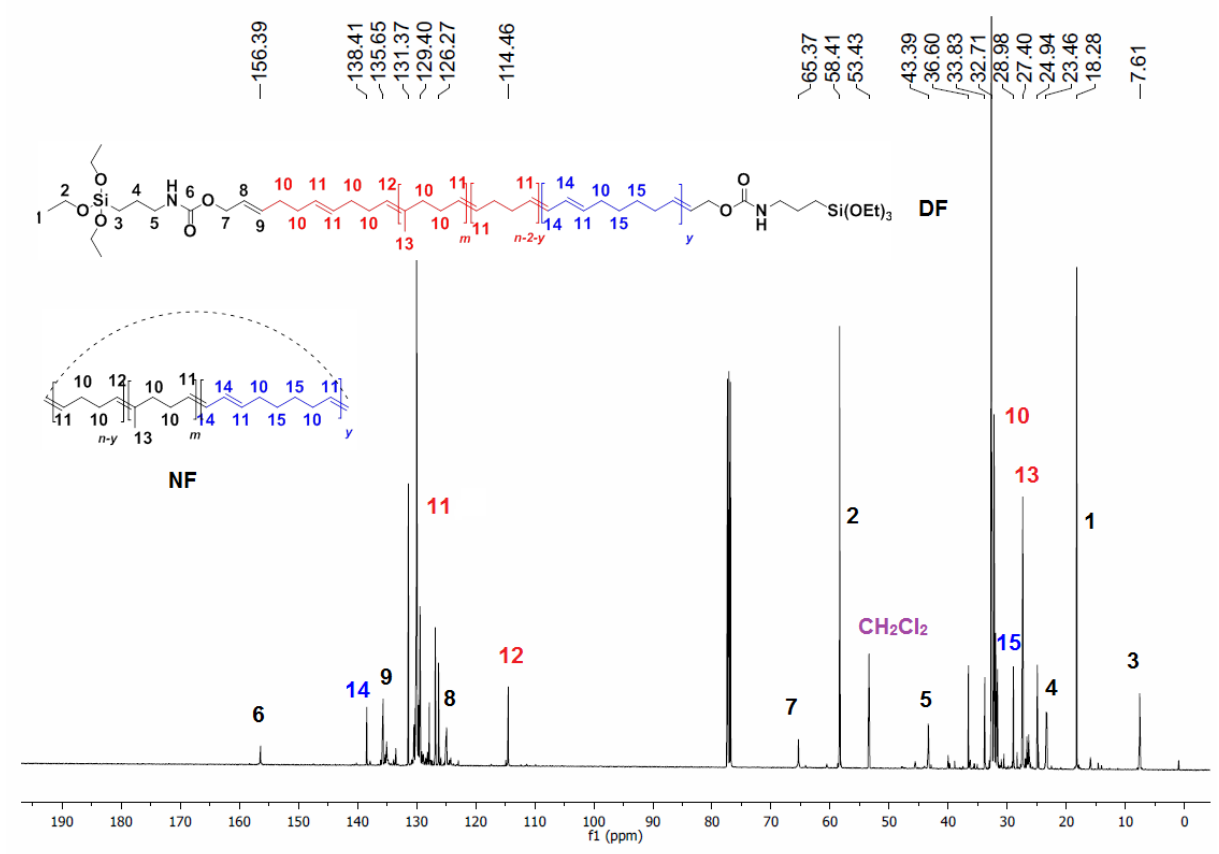

Figure S3. ${ }^{13} \mathrm{C}\left\{{ }^{1} \mathrm{H}\right\} \mathrm{NMR}\left(100 \mathrm{MHz}, \mathrm{CDCl}_{3}, 23{ }^{\circ} \mathrm{C}\right.$ of a crude $\alpha, \omega$-bis(trialkoxysilyl) telechelic P(BD-co-IP) sample prepared by CM depolymerization of P3 using $\mathbf{G 2}$ in the presence of CTA 1 (Table 2, entry 15).

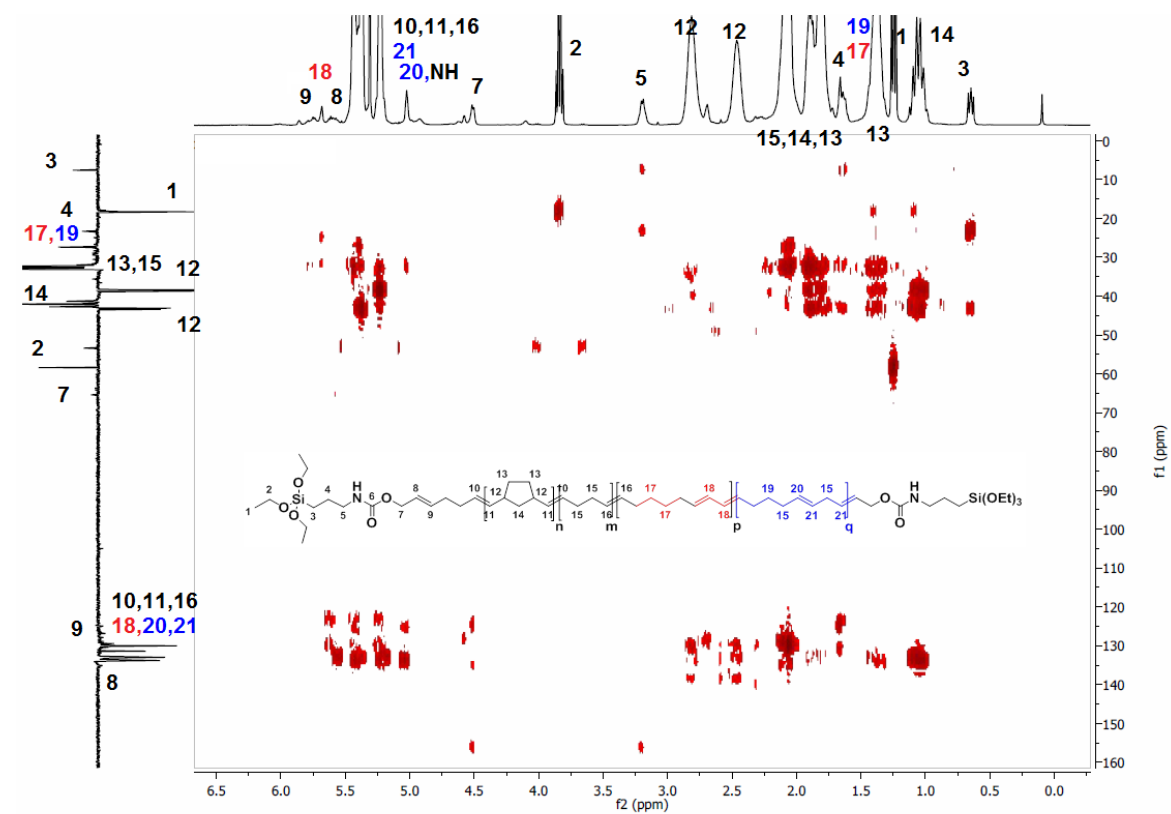

Figure S4. ${ }^{1} \mathrm{H}_{-}{ }^{13} \mathrm{C}$ (DEPT) HMBC NMR spectrum $\left(400 \mathrm{MHz}, \mathrm{CDCl}_{3}, 23{ }^{\circ} \mathrm{C}\right)$ of a crude $\alpha, \omega$-bis(trialkoxysilyl) telechelic copolymer $\mathrm{P}(\mathrm{BD}-\mathrm{co}-\mathrm{NB})$ prepared by $\mathrm{CM}$ depolymerization of PBD (P1) and ROMP/CM of NB using $\mathbf{G 2}$ in the presence of CTA 1 (Table 3, entry 6). 


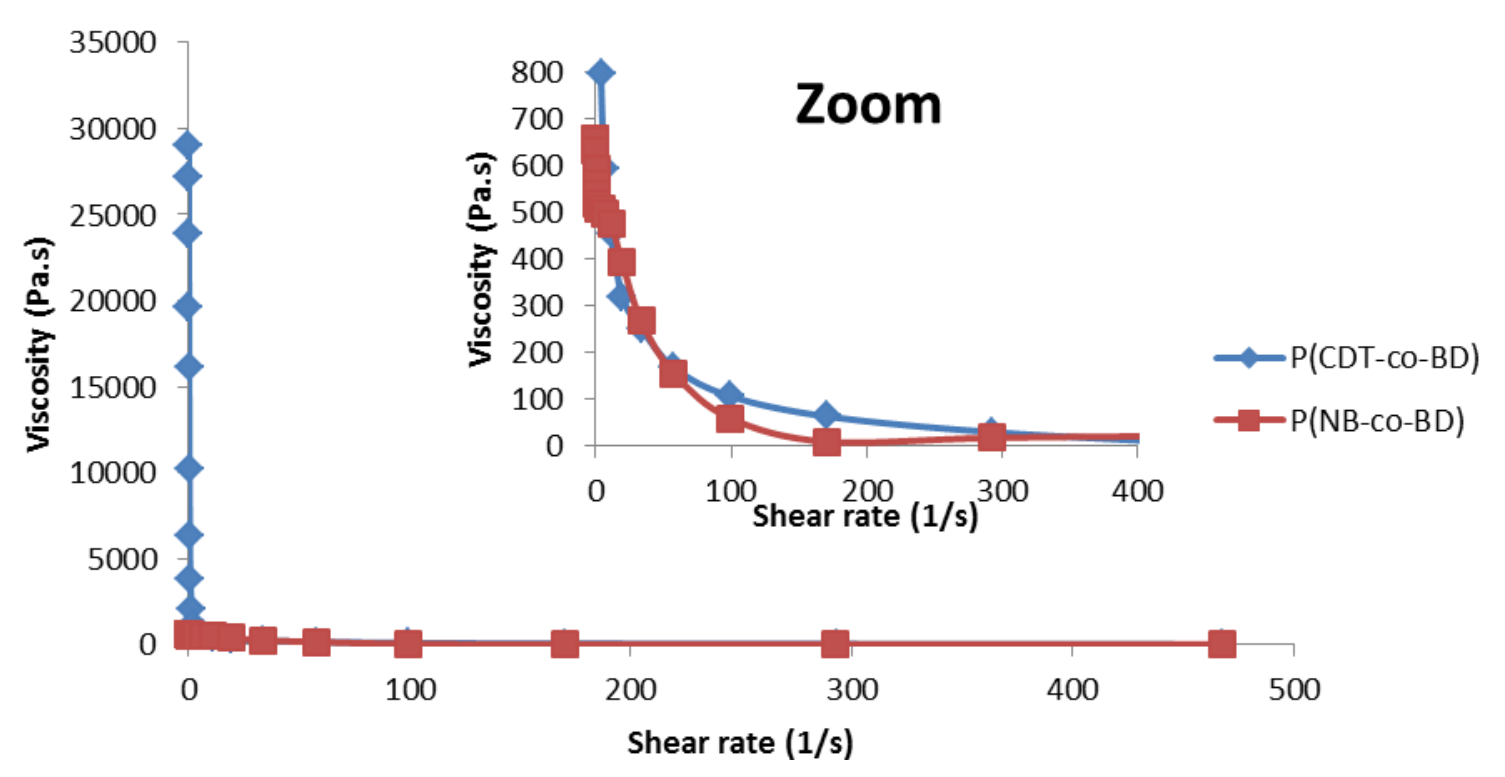

Figure S5. Flow curves of $\alpha, \omega$-bis(trialkoxysilyl) telechelic copolyolefin samples prepared from CM depolymerization of PBD (P1) and ROMP of CDT and NB using catalyst $\mathbf{G 2}$ in the presence of CTA 1 (Table 4, entries 1-2).

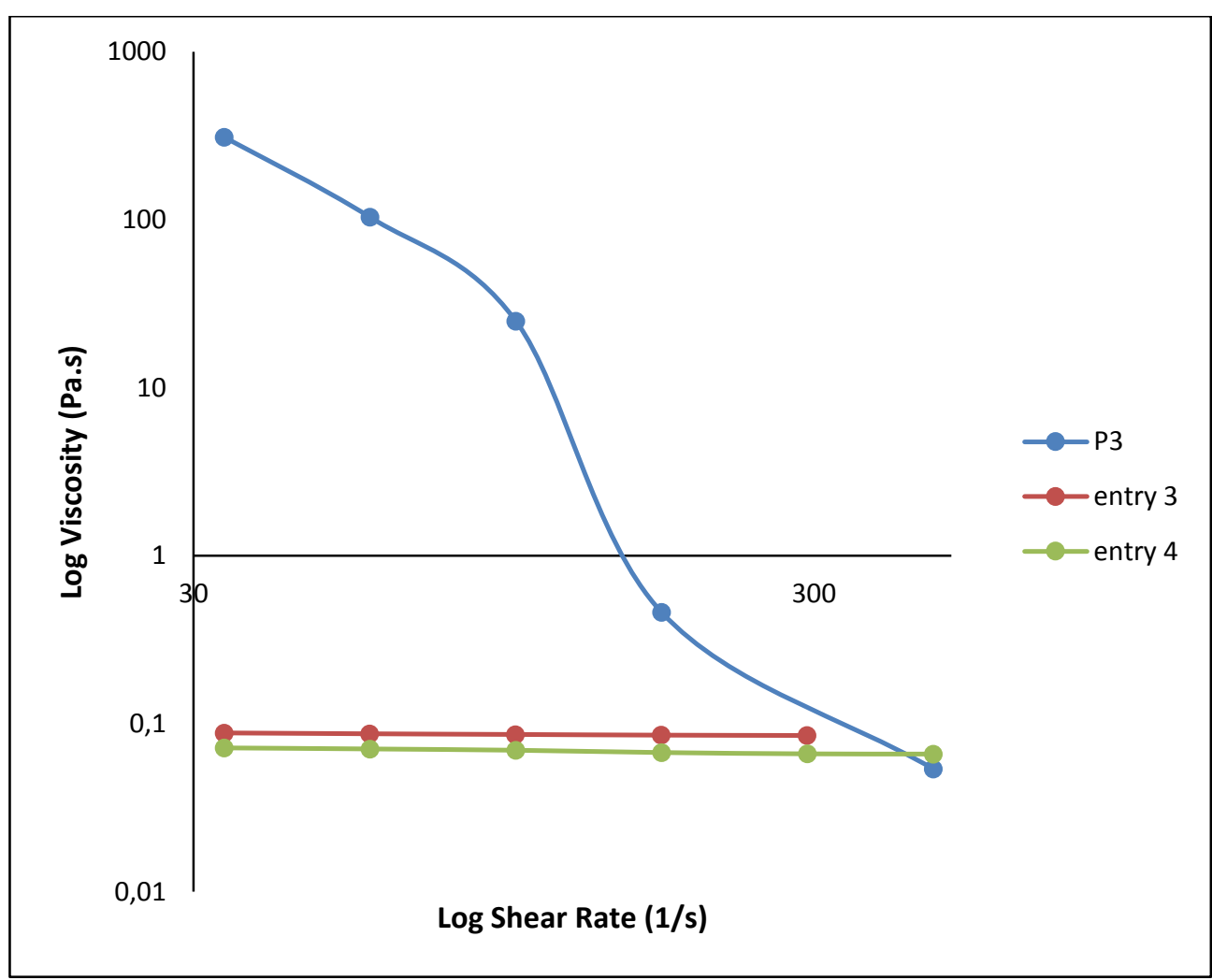

Figure S6. Flow curves of Kuraray LIR390 (P3, blue) and copolymer samples prepared from the depolymerization of P3 using G2 and CTA 1 (Table 4, entries 3-4, red). 


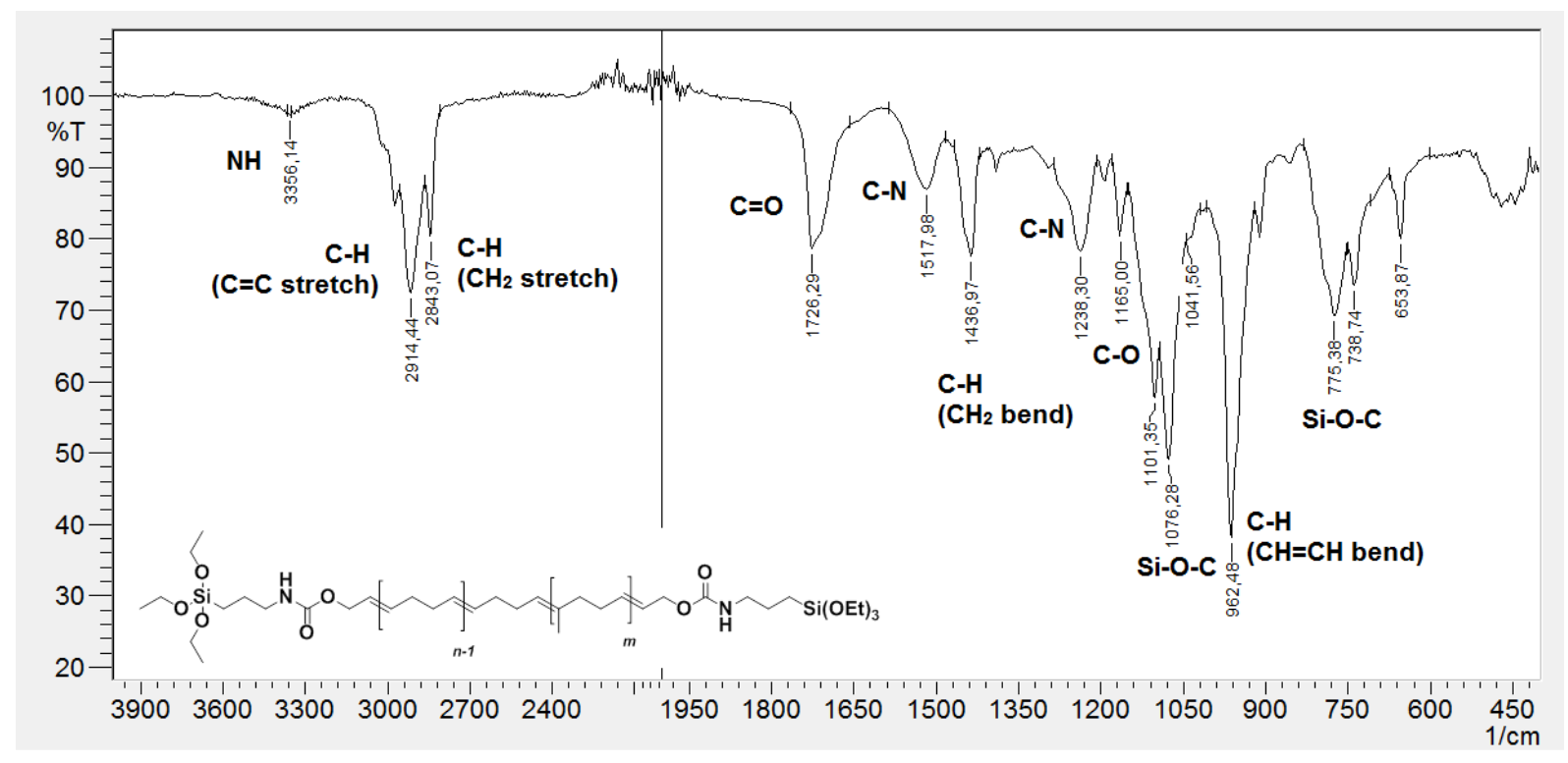

Figure S7. FTIR spectrum of a crude $\alpha, \omega$-bis(trialkoxysilyl) telechelic copolymer prepared by CM depolymerization of $\mathrm{P}(\mathrm{BD}-\mathrm{co}$-IP) (P3) using $\mathbf{G 2}$ in the presence of CTA 1 (Table 2, entry 15). FTIR spectra of the polymers were acquired (16 scans) with a resolution of $4 \mathrm{~cm}^{-1}$ on a Shimadzu IRAffinity-1 equipped with an ATR module.

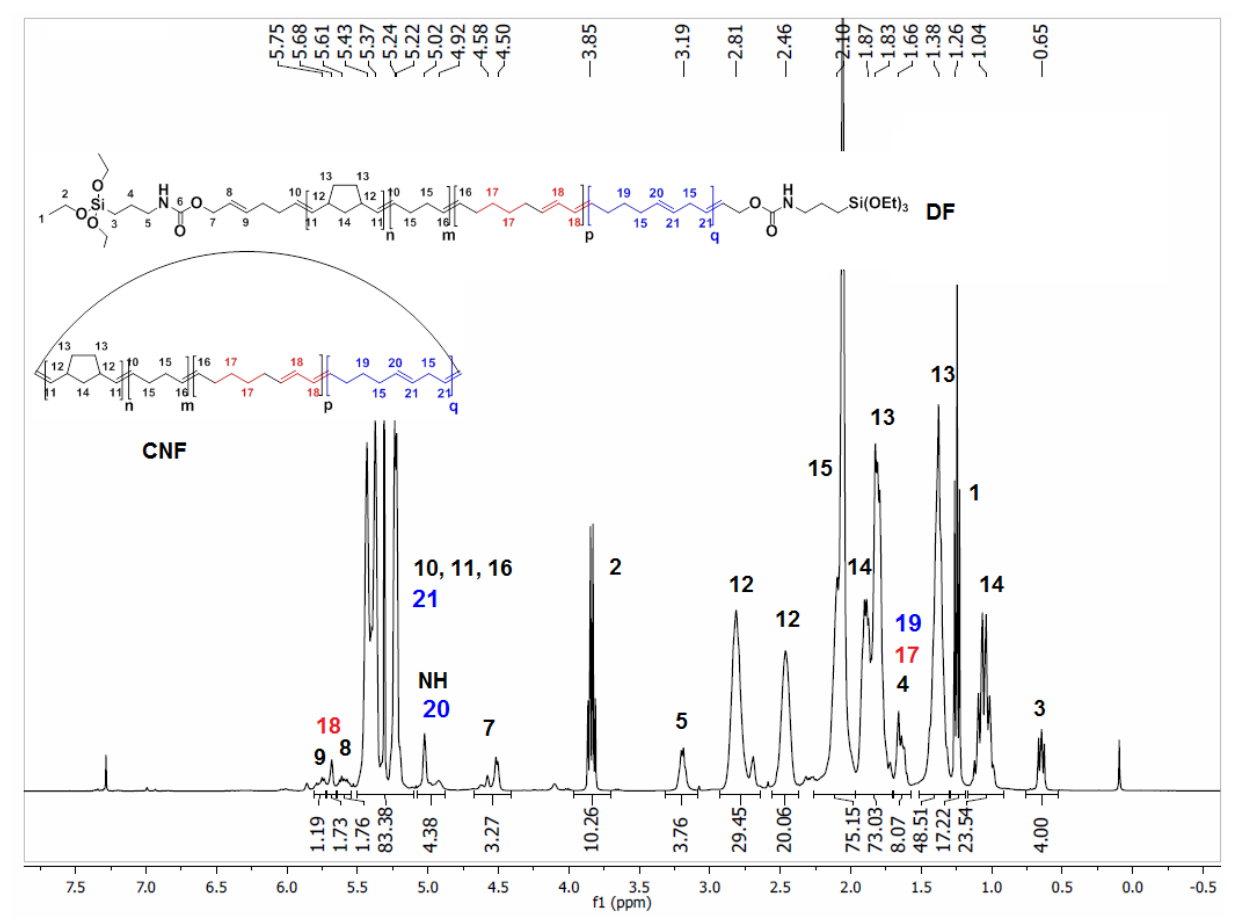

Figure S8. ${ }^{1} \mathrm{H}$ NMR spectrum $\left(500 \mathrm{MHz}, \mathrm{CDCl}_{3}, 23{ }^{\circ} \mathrm{C}\right.$ ) of a crude $\alpha, \omega$-bis(trialkoxysilyl) telechelic copolymer prepared by CM depolymerization of PBD (P1) and ROMP/CM of NB coupling using $\mathbf{G 2}$ in the presence of CTA 1 (Table 3, entry 6). 


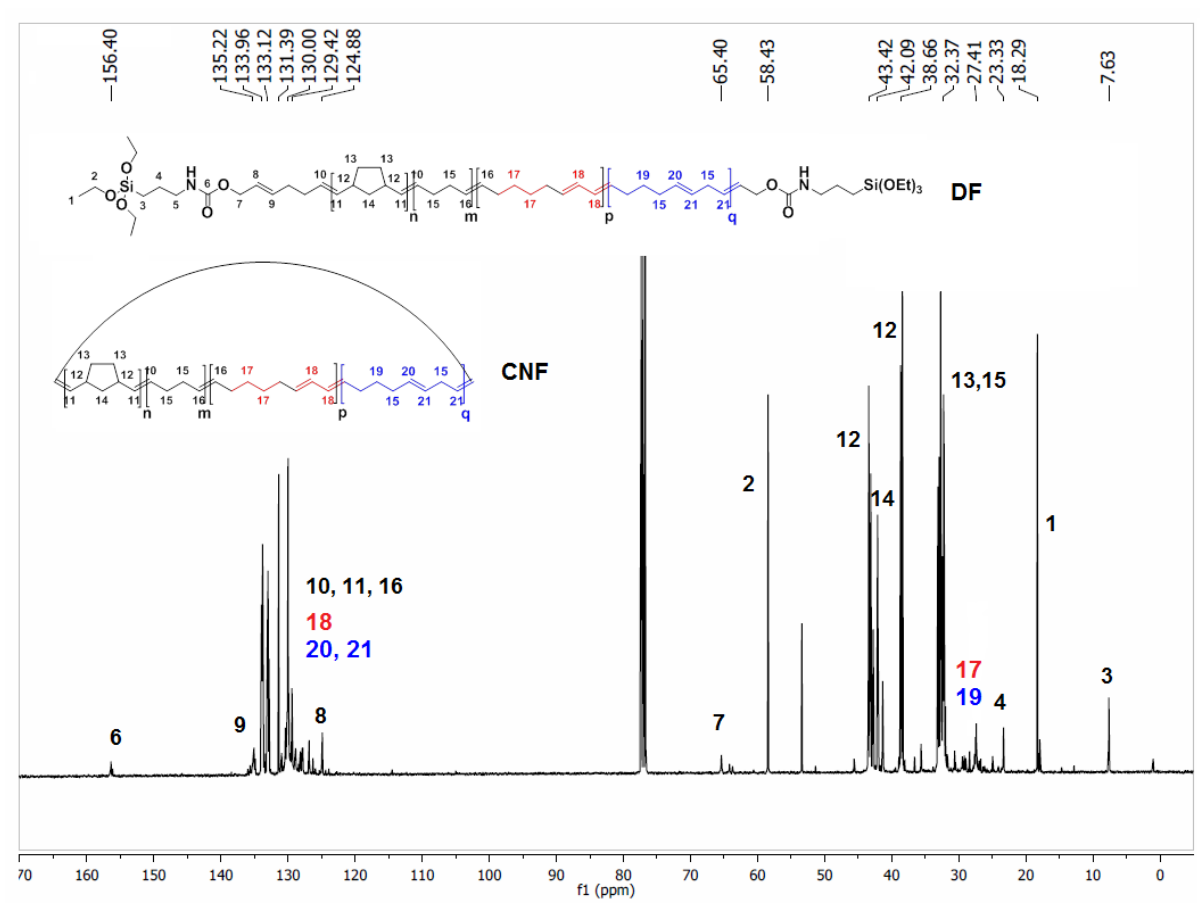

Figure S9. ${ }^{13} \mathrm{C}\left\{{ }^{1} \mathrm{H}\right\} \quad \mathrm{NMR}$ spectrum $\left(100 \mathrm{MHz}, \mathrm{CDCl}_{3}, \quad 23{ }^{\circ} \mathrm{C}\right)$ of a crude $\alpha, \omega$-bis(trialkoxysilyl) telechelic copolymer prepared by CM depolymerization of PBD (P1) and ROMP/CM of NB coupling using $\mathbf{G 2}$ in the presence of CTA 1 (Table 3, entry 6). 


\section{References}

$1 \quad$ Adhesion Science and Technology, L. H. Lee Ed., Plenum Press, New York, 1975.

2 Handbook of Adhesion, 2nd ed., D. E. Packham Ed., Wiley, West Sussex, England, 2005.

3 Handbook of Sealant Technology, K. L. Mittal and A. Pizzi Eds, CRC Press, 2009.

4 Silicone Surface Science, Advances in Silicon Science 4, M. J. Owen and P. R. Dvornic Eds., Springer, 2012.

5 Modification of Thermoplastics with Reactive Silanes and Siloxanes, J. J. Chruściel and E. Leśniak, in Thermoplastic Elastomers, A. Zaki El-Sonbati Ed., InTech, 2012.

6 T. Okamatsu and M. Ochi, Polymer, 2002, 43, 721-730.

7 V. Sambhy, B. R. Peterson and A. Sen, Langmuir, 2008, 24, 7549-7558.

8 M. Ooka and H. Ozawa, Prog. Org. Coat., 1994, 23, 325-338.

9 Y. Nomura, A. Sato, S. Sato, H. Mori and T. Endo, J. Polym. Sci., Part A: Polym. Chem., 2007, 45, 2689-2704.

10 Y. Nomura, A. Sato, S. Sato, H. Mori and T. Endo, J. Appl. Polym. Sci., 2008, 108, 236244.

11 S. Subramani, I. W. Cheong and J. H. Kim, Eur. Polym. J., 2004, 40, 2745-2755.

12 S. Subramani, J. M. Lee, I. W. Cheong and J. H. Kim, J. Appl. Polym. Sci., 2005, 98, 620631.

13 O. Laferte, S. Fouquay and R. Guillotte, Bostik SA, Eur. Pat. Appl. EP2468783A1, 2012.

14 G. Michaud, F. Simon, S. Fouquay, X. Michel, S. Guillaume, and J.-F. Carpentier, Bostik SA - Université de Rennes 1 - CNRS, WO 2016116680(A1), 2014.

15 L. Annunziata, S. Fouquay, G. Michaud, F. Simon, S. M. Guillaume and J.-F. Carpentier, Polym. Chem., 2013, 4, 1313-1316.

16 A. K. Diallo, L. Annunziata, S. Fouquay, G. Michaud, F. Simon, J.-M. Brusson, S. M. Guillaume and J.-F. Carpentier, Polym. Chem., 2014, 5, 2583-2591.

17 E. Vanbiervliet, S. Fouquay, G. Michaud, F. Simon, J.-F. Carpentier and S. M. Guillaume, Macromolecules, 2017, 50, 69-82.

18 A. K. Diallo, X. Michel, S. Fouquay, G. Michaud, F. Simon, J.-M. Brusson, J.-F. Carpentier and S. M. Guillaume, Macromolecules, 2015, 48, 7453-7465.

19 X. Michel, S. Fouquay, G. Michaud, F. Simon, J.-M. Brusson, J.-F. Carpentier and S. M. Guillaume, Polym. Chem., 2016, 7, 4810-4823. 
20 X. Michel, S. Fouquay, G. Michaud, F. Simon, J.-M. Brusson, J.-F. Carpentier and S. M. Guillaume, Polym. Chem., 2017, 8, 1177-1187.

21 G. Michaud, F. Simon, S. Fouquay, A. K. Diallo, S. Guillaume and J.-F. Carpentier, Bostik SA - Université de Rennes 1 - CNRS, Fr. Pat. Appl. 13.57241, 2013; WO 14/051897, 2014.

22 A. K. Diallo, J.-F. Carpentier, S. Guillaume, S. Fouquay, G. Michaud and F. Simon, Bostik SA - Université de Rennes 1 - CNRS, Fr. Pat. Appl. 13.57242, 2013; WO 14/051896, 2014.

23 G. Michaud, F. Simon, S. Fouquay, S. Guillaume, A. K. Diallo and J.-F. Carpentier, Bostik SA - Université de Rennes 1 - CNRS, Fr. Pat. Appl. 15.50160, 2015; WO 2016/110653, 2016.

24 G. Michaud, F. Simon, S. Fouquay, S. Guillaume, X. Michel and J.-F. Carpentier, Bostik SA - Université de Rennes 1 - CNRS, Fr. Pat. Appl. 15 50500,2015; WO 2016116680, 2016.

25 G. Michaud, F. Simon, S. Fouquay, J.-F. Carpentier, S. Guillaume and X. Michel, Bostik SA - Université de Rennes 1 - CNRS, Fr. Pat. Appl. 16 54356, 2016.

S. Fouquay, G. Michaud, F. Simon, J.-F. Carpentier, S. Guillaume and X. Michel, Bostik SA - Université de Rennes 1 - CNRS, Fr. Pat. Appl. 16 56100, 2016.

27 G. Michaud, F. Simon, S. Fouquay, X. Michel, S. Guillaume and J.-F. Carpentier, Bostik SA - Université de Rennes 1 - CNRS, Fr. Pat. Appl. 16 59062, 2016.

G. Michaud, F. Simon, S. Fouquay, X. Michel, S. Guillaume, J.-F. Carpentier, Bostik SA - Université de Rennes 1 - CNRS, Fr. Pat. Appl. 16 59061, 2016.

29 Handbook of Adhesion Technology, L. F. M. da Silva, A. Öchsner, R. D. Adams Eds, Springer-Verlag Berlin Heidelberg, 2011.

M. D. Watson and K. B. Wagener, J. Polym. Sci., Part A: Polym. Chem., 1999, 37, $1857-1861$.

31 B. Marciniec, E. Malecka, J. Gulinski, M. Grundwald-Wyspianska and M. Lewandowski, Can. J. Chem., 2001, 79, 775-779.

32 B. Marciniec, M. Lewandowski, J. Gulinski, A. F. Noels, A. Demonceau, E. Matecka and D. Janb, Polymer, 2000, 41, 827-830.

J. C. Marmo and K. B. Wagener, Macromolecules, 1993, 26, 2137-2138.

J. C. Marmo and K. B. Wagener, Macromolecules, 1995, 28, 2602-2606.

M. D. Schulz, R. R. Ford and K. B. Wagener, Polym. Chem., 2013, 4, 3656-3658. 
36 J. C. Marmo and K. B. Wagener, Macromol. Rapid Commun., 1995, 16, 557-561.

37 V. Lapinte, L. Fontaine, V. Montembault, I. Campistron and D. Reyx, J. Mol. Catal. A: Chem., 2002, 190, 117-129.

38 K. B. Wagener, R. D. Puts and D. W. Smith, Jr., Makromol. Chem., Rapid Commun., 1991, $12,419-425$.

39 A. Mouawia, A. Nourry, A.-C. Gaumont, J.-F. Pilard and I. Dez, ACS Sustainable Chem. Eng., 2017, 5, 696-700.

40 F. Sadaka, I. Campistron, A. Laguerre and J.-F. Pilard, Polym. Degrad. Stab., 2013, 98, 736-742.

41 S. S. Solanky, I. Campistron, A. Laguerre and J.-F. Pilard, Macromol: Chem. Phys., 2005, 206, 1057-1063.

42 N. Saetung, I. Campistron, S. Pascual, J.-F. Pilard and L. Fontaine, Macromolecules, 2011, 44, 784-794.

43 T. Ohishi, K. Suyama, S. Kamimura, M. Sakada, K. Imato, S. Kawahara, A. Takahara and H. Otsuka, Polymer, 2015, 78, 145-153.

44 L. Friebe, O. Nuyken and W. Obrecht, Adv. Polym. Sci., 2006, 204, 1-154.

45 Although the molar mass of these PBD (co)polymers (selected because industrially relevant adhesive synthons) were rather low $\left(<20000\right.$ g.mol $\left.{ }^{-1}\right)$, the strategy presently established with P1-P3 could be extended to other commercially available (in pure form or as a waste) higher molar mass polydienes.

46 A. Dewaele, T. Renders, B. Yu, F. Verpoort and B. F. Sels, Catal. Sci. \& Technol., 2016, 6, 7708-7717.

47 G. W. Coates, R. Grubbs, J. Am. Chem. Soc. 1996, 118, 229-230.

48 The objectives at this stage is to provide a simple, soft and rapid purification procedure of the commercial polymers for the depolymerization/metathesis reactions to efficiently proceed, and not to necessarily remove non-rubber impurities.

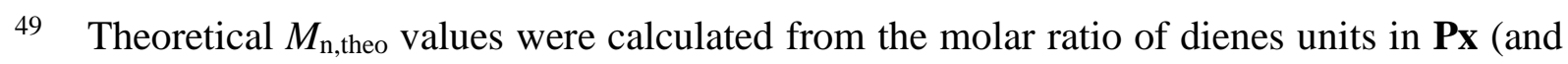
of CDT or NB for the tandem CM depolymerization of PBD and functional ROMP/CM)to-CTA (considering the actual conversion of CTA as determined by NMR), assuming only the formation of difunctionalized macromolecules (DF).

50 S. Hilf, and A. F. M. Kilbinger, Nat. Chem., 2009, 1, 537-546.

51 C. Larroche, J. P. Laval, A. Lattes, M. Leconte, F. Quignard and J. M. Basset, J. Chem. Soc., Chem. Commun., 1983, 5, 220-221. 
52 C. W. Bielawski and R. H. Grubbs, Prog. Polym. Sci., 2007, 32, 1-29.

53 J. Finter, G. Wegner, Makromol. Chem. 1981, 182, 1859.

54 J. J. Benvenuta-Tapia, J. A. Tenorio-Lopez, R. Herrera-Nájera, L. Ríos-Guerrero, Polym. Eng. Sci. 2009, 49, 1-10. 